\title{
COVID-19 Outbreak Prediction with Machine Learning
}

\author{
Sina F. Ardabili ${ }^{1}$, Amir Mosavi 2,3,*, Pedram Ghamisi ${ }^{4}$, Filip Ferdinand ${ }^{2}$, Annamaria R. \\ Varkonyi-Koczy ${ }^{2}$, Uwe Reuter ${ }^{3}$, Timon Rabczuk ${ }^{5}$, Peter M. Atkinson ${ }^{6}$ \\ 1 Department of Biosystem engineering, University of Mohaghegh Ardabili, Ardabil, Iran; \\ s.ardabili@ieee.org \\ 2 Department of Mathematics and Informatics, J. Selye University, 94501 Komarno, Slovakia; \\ 3 Faculty of Civil Engineering, Technische Universität Dresden, 01069 Dresden, Germany; \\ 4 Machine Learning Group, Exploration Division, Helmholtz Institute Freiberg for Resource Technology, \\ Helmholtz-Zentrum Dresden-Rossendorf, Dresden, Germany; \\ 5 Institute of Structural Mechanics, Bauhaus-Universität Weimar, 99423 Weimar, Germany; \\ 6 Lancaster Environment Centre, Lancaster University, Lancaster LA1 4YQ, UK; \\ * Correspondence: a.mosavi@ieee.org
}

Received: date; Accepted: date; Published: date

\begin{abstract}
Several outbreak prediction models for COVID-19 are being used by officials around the world to make informed-decisions and enforce relevant control measures. Among the standard models for COVID-19 global pandemic prediction, simple epidemiological and statistical models have received more attention by authorities, and they are popular in the media. Due to a high level of uncertainty and lack of essential data, standard models have shown low accuracy for long-term prediction. Although the literature includes several attempts to address this issue, the essential generalization and robustness abilities of existing models needs to be improved. This paper presents a comparative analysis of machine learning and soft computing models to predict the COVID-19 outbreak as an alternative to SIR and SEIR models. Among a wide range of machine learning models investigated, two models showed promising results (i.e., multi-layered perceptron, MLP, and adaptive network-based fuzzy inference system, ANFIS). Based on the results reported here, and due to the highly complex nature of the COVID-19 outbreak and variation in its behavior from nation-to-nation, this study suggests machine learning as an effective tool to model the outbreak. This paper provides an initial benchmarking to demonstrate the potential of machine learning for future research. Paper further suggests that real novelty in outbreak prediction can be realized through integrating machine learning and SEIR models.
\end{abstract}

Keywords: COVID-19; Deep learning, time-series data, Huge data, Coronavirus disease; Coronavirus; SARS-CoV-2; model; prediction; machine learning

\section{Introduction}

Access to accurate outbreak prediction models is essential to obtain insights into the likely spread and consequences of infectious diseases. Governments and other legislative bodies rely on insights from prediction models to suggest new policies and to assess the effectiveness of the enforced policies [1]. The novel Coronavirus disease (COVID-19) has been reported to infect more than 2 million people, with more than 132,000 confirmed deaths worldwide. The recent global COVID-19 pandemic has exhibited a nonlinear and complex nature [2]. In addition, the outbreak has differences with other recent outbreaks, which brings into question the ability of standard models to deliver accurate results [3]. Besides the numerous known and unknown variables involved in the spread, the complexity of population-wide behavior in various geopolitical areas and differences in containment strategies had dramatically increased model uncertainty [4]. Consequently, standard epidemiological models face new challenges to deliver more reliable results. To overcome this challenge, many novel 
models have emerged which introduce several assumptions to modeling (e.g., adding social distancing in the form of curfews, quarantines, etc.) [5-7].

To elaborate on the effectiveness of enforcing such assumptions understanding standard dynamic epidemiological (e.g., susceptible-infected-recovered, SIR) models is essential [8]. The modeling strategy is formed around the assumption of transmitting the infectious disease through contacts, considering three different classes of well-mixed populations; susceptible to infection (class $S$ ), infected (class $I$ ), and the removed population (class $R$ is devoted to those who have recovered, developed immunity, been isolated or passed away). It is further assumed that the class I transmits the infection to class $S$ where the number of probable transmissions is proportional to the total number of contacts [9-11]. The number of individuals in the class $S$ progresses as a time-series, often computed using a basic differential equation as follows:

$$
\frac{d S}{d t}=-\alpha S I
$$

where $I$ is the infected population, and $S$ is the susceptible population both as fractions. $\alpha$ represents the daily reproduction rate of the differential equation, regulating the number of susceptible infectious contacts. The value of $S$ in the time-series produced by the differential equation gradually declines. Initially, it is assumed that at the early stage of the outbreak $S \approx 1$ while the number of individuals in class $I$ is negligible. Thus, the increment $\frac{d I}{d t}$ becomes linear and the class $I$ eventually can be computed as follows:

$$
\frac{d I}{d t}=\alpha S I-\beta I
$$

where $\beta$ regulates the daily rate of new infections by quantifying the number of infected individuals competent in the transmission. Furthermore, the class $R$, representing individuals excluded from the spread of infection, is computed as follows:

$$
\frac{d R}{d t}=\beta I
$$

Under the unconstrained conditions of the excluded group, Eq. 3, the outbreak exponential growth can be computed as follows:

$$
I(t) \approx I_{0} \exp \{(\alpha-\beta)\}
$$

The outbreaks of a wide range of infectious diseases have been modeled using Eq. 4. However, for the COVID-19 outbreak prediction, due to the strict measures enforced by authorities, the susceptibility to infection has been manipulated dramatically. For example, in China, Italy, France, Hungary and Spain the SIR model cannot present promising results, as individuals committed voluntarily to quarantine and limited their social interaction. However, for countries where containment measures were delayed (e.g., United States) the model has shown relative accuracy [12]. Figure. 1 shows the inaccuracy of conventional models applied to the outbreak in Italy by comparing the actual number of confirmed infections and epidemiological model predictions ${ }^{1}$. SEIR models, by considering the significant incubation period during which individuals are infected, showed increased model accuracy for the Varicella and Zika outbreaks $[13,14]$. SEIR models assume that the incubation period is a random variable and similarly to the SIR model, there is a disease-freeequilibrium $[15,16]$. It should be noted, however, that standard SIR and SEIR models will not fit well where the parameters related to social mixing and, thus, the contact network are non-stationary through time [17]. A key cause of non-stationarity is where the social mixing (which determines the contact network) changes through time. Social mixing determines the reproductive number $R_{0}$ which is the number of susceptible individuals that an infected person will infect. Where $R_{0}$ is less than 1 the epidemic will die out. Where it is greater than 1 it will spread. $R_{0}$ for COVID-19

\footnotetext{
1 This trend obviously depends on the approach chosen to model the outbreak. For example, SEIR model performs usually better than SIR model.
} 
prior to lockdown was estimated as a massive 4 [1] presenting a pandemic. It is expected that lockdown measures should bring $R_{0}$ down to less than 1 . The KEY reason why SEIR models are difficult to fit for COVID-19 is non-stationarity of mixing, caused by nudging (step-by-step) intervention measures. A further drawback of conventional epidemiological models is the short leadtime. To evaluate the performance of the models, the median success of the outbreak prediction presents useful information. The median prediction factor can be calculated as follows:

$$
f=\frac{\text { Prediction }}{\text { True value }}
$$

As the lead-time increases, the accuracy of the model declines. For instance, for the COVID-19 outbreak in Italy, the accuracy of the model for more than 5-days-in-the-future reduces from $f=1$ for the first five days to $f=0.86$ for day 6 [12]. Overall, the standard epidemiological models can be effective and reliable only if (a) the social interactions are stationary through time (i.e., no changes in interventions or control measures), and (b) there exists a great deal of knowledge of class $R$ with which to compute Eq. 3. Often to acquire information on class $R$, several novel models included data from social media or call data records (CDR), which showed promising results [18-25]. However, observation of the behavior of COVID-19 in several countries demonstrates a high degree of uncertainty and complexity [26]. Thus, for epidemiological models to be able to deliver reliable results, they must be adapted to the local situation based on insights into susceptibility to infection due to changes in public health interventions, and the various states in the SIR/SEIR model [27]. This imposes a huge limit on the generalization ability and robustness of conventional models. Advancing accurate models with a great generalization ability to be scalable to model both the regional and global pandemic is, thus, essential [28].

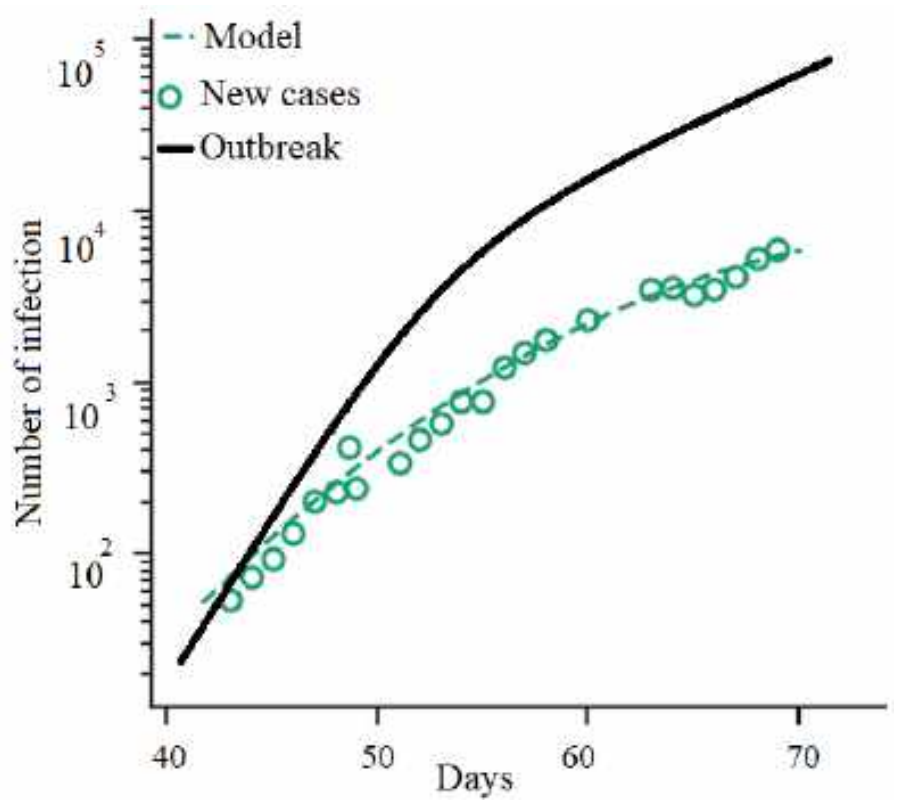

Figure 1. Italy's COVID-19 outbreak: the actual number of confirmed infections vs. epidemiological model.

Due to the complexity and the large-scale nature of the problem in developing epidemiological models, machine learning (ML) has recently gained attention for building outbreak prediction models. ML approaches aim at developing models with higher generalization ability and greater prediction reliability for longer lead-times [29-33]. 
Although ML methods were used in modeling former pandemics (e.g., Ebola, Cholera, swine fever, H1N1 influenza, dengue fever, Zika, oyster norovirus [8,34-43]), there is a gap in the literature for peer-reviewed papers dedicated to COVID-19. Table 1 represents notable ML methods used for outbreak prediction. These ML methods are limited to the basic methods of random forest, neural networks, Bayesian networks, Naïve Bayes, genetic programming and classification and regression tree (CART). Although ML has long been established as a standard tool for modeling natural disasters and weather forecasting [44,45], its application in modeling outbreak is still in the early stages. More sophisticated ML methods (e.g., hybrids, ensembles) are yet to be explored. Consequently, the contribution of this paper is to explore the application of ML for modeling the COVID-19 pandemic. This paper aims to investigate the generalization ability of the proposed ML models and the accuracy of the proposed models for different lead-times.

Table 1. Notable ML methods for outbreak prediction

\begin{tabular}{|c|c|c|c|}
\hline Authors & Journal & Outbreak infection & Machine \\
\hline [39] & $\begin{array}{l}\text { Transboundary and } \\
\text { Emerging Diseases }\end{array}$ & Swine fever & Random Forest \\
\hline [35] & Geospatial Health & Dengue fever & Neural Network \\
\hline [42] & BMC Research Notes & Influenza & Random Forest \\
\hline [41] & $\begin{array}{l}\text { Journal of Public } \\
\text { Health Medicine }\end{array}$ & Dengue/Aedes & Bayesian Network \\
\hline [38] & Informatica & Dengue & LogitBoost \\
\hline [8] & $\begin{array}{l}\text { Global Ecology and } \\
\text { Biogeography }\end{array}$ & H1N1 flu & Neural Network \\
\hline [34] & Current Science & Dengue & $\begin{array}{l}\text { Adopted multi-regression } \\
\text { and Naïve Bayes }\end{array}$ \\
\hline [36] & $\begin{array}{l}\text { Environment } \\
\text { International }\end{array}$ & Oyster norovirus & Neural Network \\
\hline [37] & Water Research & Oyster norovirus & Genetic programming \\
\hline [43] & $\begin{array}{c}\text { Infectious Disease } \\
\text { Modelling }\end{array}$ & Dengue & $\begin{array}{c}\text { Classification and } \\
\text { regression tree (CART) }\end{array}$ \\
\hline
\end{tabular}

The state-of-the-art machine learning methods for outbreak prediction modeling demonstrates two major research gaps for machine learning to address. Firstly, advancement in time series prediction of outbreak and secondly improvement of SIR and SEIR models. Considering the drawbacks to the existing SIR and SEIR, machine learning can certainly contribute. This paper contributes to the advancement of time series prediction of COVID-19. Consequently, an initial benchmarking is given to demonstrate the potential of machine learning for future research. Paper further suggests that real novelty in outbreak prediction can be realized through integrating machine learning and SEIR models.

The rest of this paper is organized as follows. Section two describes the methods and materials. The results are given in section three. Sections four and five present the discussion and the conclusions, respectively.

\section{Materials and Methods}

Data were collected from https://www.worldometers.info/coronavirus/country for five countries, including Italy, Germany, Iran, USA, and China on total cases over 30 days. Figure 2 presents the total case number (cumulative statistic) for the considered countries. Currently, to contain the outbreak, the governments have implemented various measures to reduce transmission through inhibiting people's movements and social activities. Although for advancing the epidemiological models information on changes in social distancing is essential, for modeling with 
machine learning no assumption is required. As can be seen in Figure 2, the growth rate in China is greater than that for Italy, Iran, Germany and the USA in the early weeks of the disease.

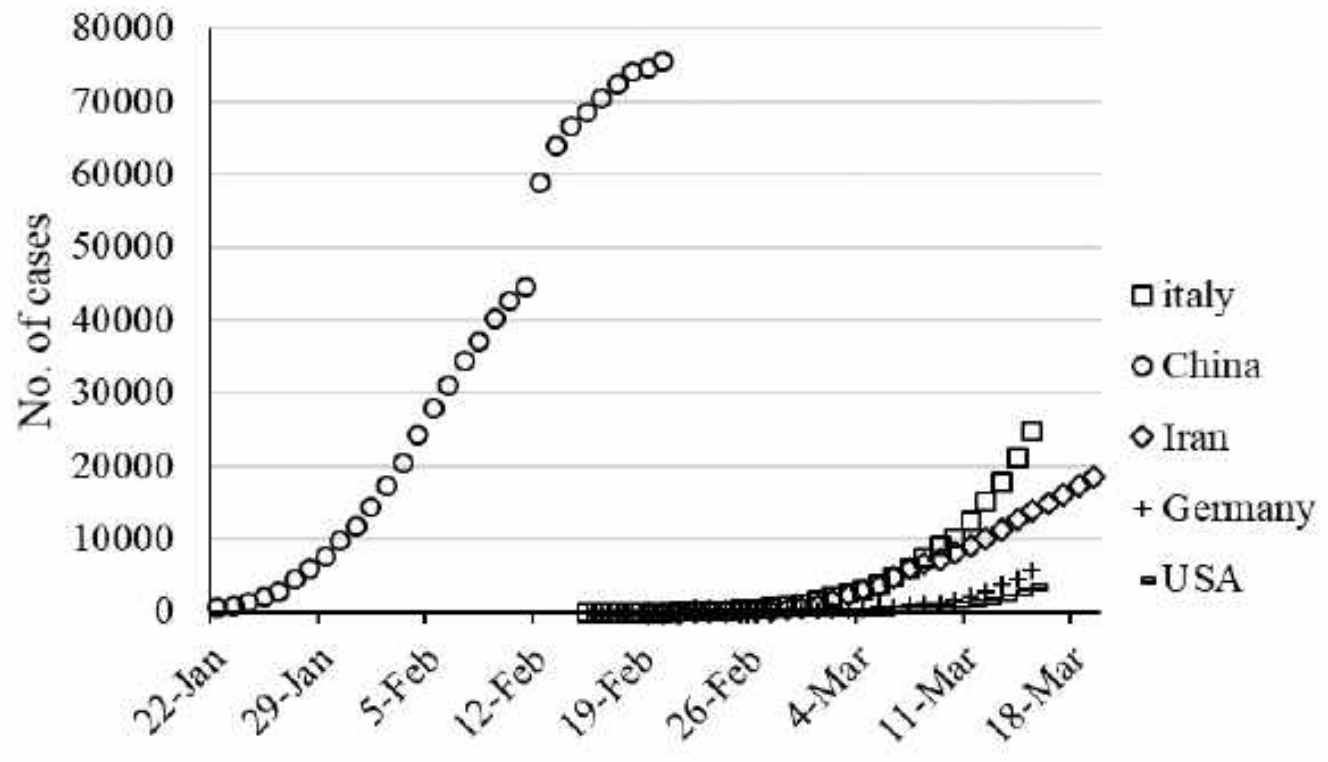

Figure 2. Cumulative number of cases for five countries during thirty days (https://www.worldometers.info/coronavirus/country)

The next step is to find the best model for the estimation of the time-series data. Logistic, Linear, Logarithmic, Quadratic, Cubic, Compound, Power and exponential equations (Table 2) are employed to develop the desired model. These models are generally not good fits for outbreak prediction beyond the available data. In this study, through parameter tuning we aim at finding the optimal performance of these models. The model with the best performance is later used for comparative analysis.

Table 2. Models for mathematical forecasting

\begin{tabular}{ccc}
\hline Model description & Model name & Equation number \\
\hline $\mathrm{R}=\mathrm{A} /\left(1+\exp \left(\left(\left(4^{*} \mu\right)^{*}(\mathrm{~L}-\mathrm{x}) / \mathrm{A}\right)+2\right)\right)$ & Logistic & $(6)$ \\
$\mathrm{R}=\mathrm{Ax}-\mathrm{B}$ & Linear & $(7)$ \\
$\mathrm{R}=\mathrm{A}+\mathrm{Blog}(\mathrm{x})$ & Logarithmic & $(8)$ \\
$\mathrm{R}=\mathrm{A}+\mathrm{B} x+\mathrm{C} \mathrm{x}^{2}$ & Quadratic & $(9)$ \\
$\mathrm{R}=\mathrm{A}+\mathrm{B} x+\mathrm{Cx}^{2}+\mathrm{Dx}^{3}$ & Cubic & $(10)$ \\
$\mathrm{R}=\mathrm{AB} B^{\mathrm{n}}$ & Compound & $(11)$ \\
$\mathrm{R}=\mathrm{Ax}$ & Power & $(12)$ \\
$\mathrm{R}=\mathrm{AEXP}(\mathrm{Bx})$ & Exponential & $(13)$ \\
\hline
\end{tabular}

$\mathrm{A}, \mathrm{B}, \mathrm{C}, \mu$, and $\mathrm{L}$ are parameters (constants) that characterize the above-mentioned functions. These constants need to be estimated to develop an accurate estimation model. One of the goals of this study was to model time-series data based on the logistic microbial growth model. For this purpose, the modified equation of logistic regression was used to estimate and predict the prevalence (i.e., I/Population at a given time point) of disease as a function of time. Estimation of the parameters 
was performed using evolutionary algorithms like GA, particle swarm optimizer, and the grey wolf optimizer. These algorithms are discussed in the following.

\section{Evolutionary algorithms}

Evolutionary algorithms (EA) are powerful tools for solving optimization problems through intelligent methods. These algorithms are often inspired by natural processes to search for all possible answers as an optimization problem [46-48]. In the present study, the frequently used algorithms, (i.e., genetic algorithm (GA), particle swarm optimizer (PSO) and grey wolf optimizer (GWO)) are employed to estimate the parameters by solving a cost function.

\section{Genetic Algorithm (GA)}

GAs are considered a subset of "computational models" inspired by the concept of evolution [49]. These algorithms use "Potential Solutions" or "Candidate Solutions" or "Possible Hypotheses" for a specific problem in a "chromosome-like" data structure. GA maintains vital information stored in these chromosome data structures by applying "Recombination Operators" to chromosome-like data structures [50-53]. In many cases, GAs are employed as "Function Optimizer" algorithms, which are algorithms used to optimize "Objective Functions." Of course, the range of applications that use the GA to solve problems is very wide [52,54]. The implementation of the GA usually begins with the production of a population of chromosomes generated randomly and bound up and down by the variables of the problem. In the next step, the generated data structures (chromosomes) are evaluated, and chromosomes that can better display the optimal solution of the problem are more likely to be used to produce new chromosomes. The degree of "goodness" of an answer is usually measured by the population of the current candidate's answers [55-59]. The main algorithm of a GA process is demonstrated in Figure 3.

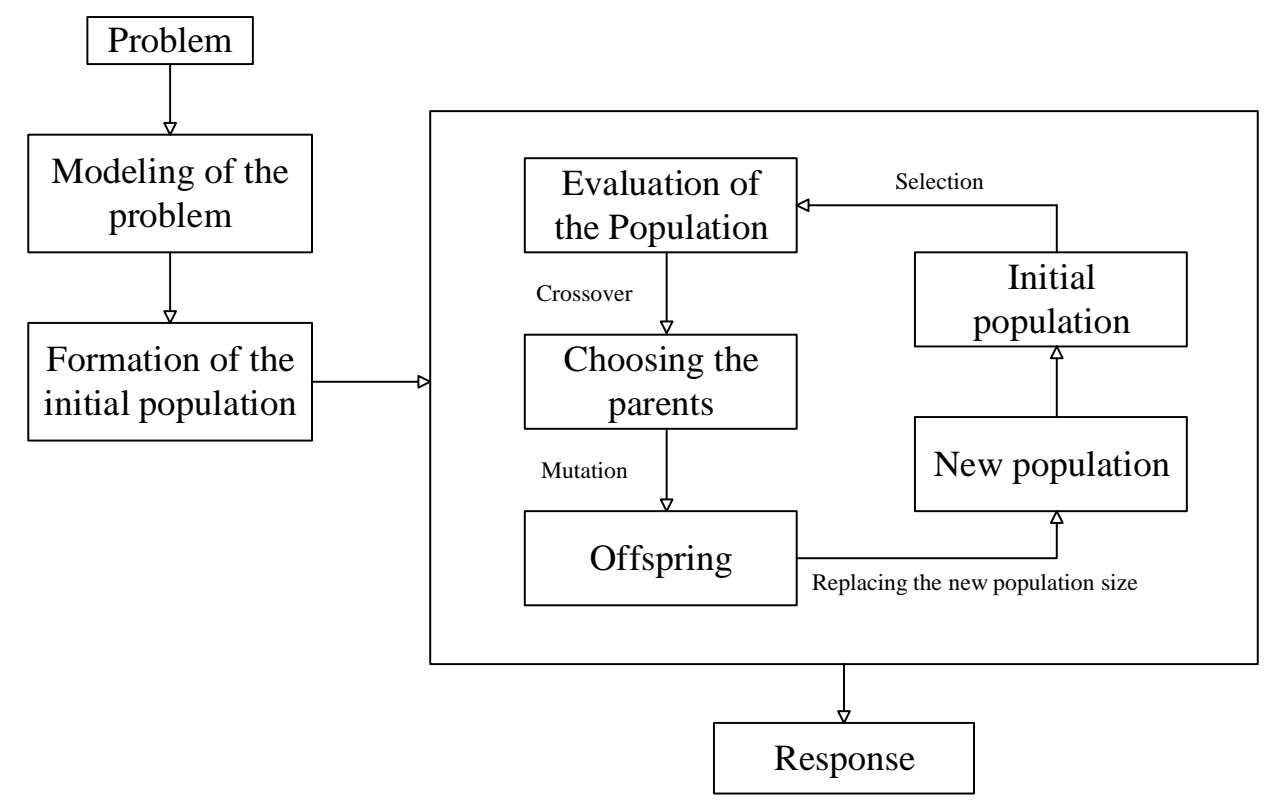

Figure 3. GA algorithm

In the present study, GA [59] was employed for estimation of the parameters of Eq. 6 to 13. The population number was selected to be 300 and the maximum generation (as iteration number) was determined to be 500 according to different trial and error processes to reduce the cost function value. The cost function was defined as the mean square error between the target and estimated values according to Eq. 14: 


$$
M S E=\sqrt{\frac{(E S-T)^{2}}{N}}
$$

where, Es refer to estimated values, $T$ refers to the target values and $N$ refers to the number of data.

\section{Particle Swarm Optimization (PSO)}

In 1995, Kennedy and Eberhart [60] introduced the PSO as an uncertain search method for optimization purposes. The algorithm was inspired by the mass movement of birds looking for food. A group of birds accidentally looked for food in a space. There is only one piece of food in the search space. Each solution in PSO is called a particle, which is equivalent to a bird in the bird's mass movement algorithm. Each particle has a value that is calculated by a competency function which increases as the particle in the search space approaches the target (food in the bird's movement model). Each particle also has a velocity that guides the motion of the particle. Each particle continues to move in the problem space by tracking the optimal particles in the current state [60-62]. The PSO method is rooted in Reynolds' work, which is an early simulation of the social behavior of birds. The mass of particles in nature represents collective intelligence. Consider the collective movement of fish in water or birds during migration. All members move in perfect harmony with each other, hunt together if they are to be hunted, and escape from the clutches of a predator by moving another prey if they are to be preyed upon [63-65]. Particle properties in this algorithm include [65-67]:

- $\quad$ Each particle independently looks for the optimal point.

- Each particle moves at the same speed at each step.

- Each particle remembers its best position in the space.

- The particles work together to inform each other of the places they are looking for.

- $\quad$ Each particle is in contact with its neighboring particles.

- Every particle is aware of the particles that are in the neighborhood.

- Every particle is known as one of the best particles in its neighborhood.

The PSO implementation steps can be summarized as: the first step establishes and evaluates the primary population. The second step determines the best personal memories and the best collective memories. The third step updates the speed and position. If the conditions for stopping are not met, the cycle will go to the second step.

The PSO algorithm is a population-based algorithm $[68,69]$. This property makes it less likely to be trapped in a local minimum. This algorithm operates according to possible rules, not definite rules. Therefore, PSO is a random optimization algorithm that can search for unspecified and complex areas. This makes PSO more flexible and durable than conventional methods. PSO deals with nondifferential target functions because the PSO uses the information result (performance index or target function to guide the search in the problem area). The quality of the proposed route response does not depend on the initial population. Starting from anywhere in the search space, the algorithm ultimately converges on the optimal answer. PSO has great flexibility to control the balance between the local and overall search space. This unique PSO property overcomes the problem of improper convergence and increases the search capacity. All of these features make PSO different from the GA and other innovative algorithms [61,65,67].

In the present study, PSO was employed for estimation of the parameters of Eq. 6 to 13. The population number was selected to be 1000 and the iteration number was determined to be 500 according to different trial and error processes to reduce the cost function value. The cost function was defined as the mean square error between the target and estimated values according to Eq. 14 .

\section{Grey Wolf Optimizer (GWO)}

One recently developed smart optimization algorithm that has attracted the attention of many researchers is the grey wolf algorithm. Like most other intelligent algorithms, GWO is inspired by nature. The main idea of the grey wolf algorithm is based on the leadership hierarchy in wolf groups 
and how they hunt [70]. In general, there are four categories of wolves among the herd of grey wolves, alpha, beta, delta and omega. Alpha wolves are at the top of the herd's leadership pyramid, and the rest of the wolves take orders from the alpha group and follow them (usually there is only one wolf as an alpha wolf in each herd). Beta wolves are in the lower tier, but their superiority over Delta and omega wolves allows them to provide advice and help to alpha wolves. Beta wolves are responsible for regulating and orienting the herd based on alpha movement. Delta wolves, which are next in line for the power pyramid in the wolf herd, are usually made up of guards, elderly population, caregivers of damaged wolves, and so on. Omega wolves are also the weakest in the power hierarchy [70]. Eq. 15 to 18 are used to model the hunting tool:

$$
\begin{gathered}
\vec{D}=\left|\vec{C}, \overrightarrow{X_{p}}(t)-\vec{X}(t)\right| \\
\vec{X}(t+1)=\overrightarrow{X_{p}}(t)-\vec{A}, \vec{D} \\
\vec{A}=2 \vec{a}, \overrightarrow{r_{1}}-\vec{a} \\
\vec{C}=2 \overrightarrow{r_{2}}
\end{gathered}
$$

where $t$ is represents repetition of the algorithm. $\vec{A}$ and $\vec{C}$ are vectors of the prey site and the $\vec{X}$ vectors represent the locations of the grey wolves. $\vec{a}$ is linearly reduced from 2 to 0 during the repetition. $\overrightarrow{r_{1}}$ and $\overrightarrow{r_{2}}$ are random vectors where each element can take on realizations in the range [0.1]. The GWO algorithm flowchart is shown in Figure 4.

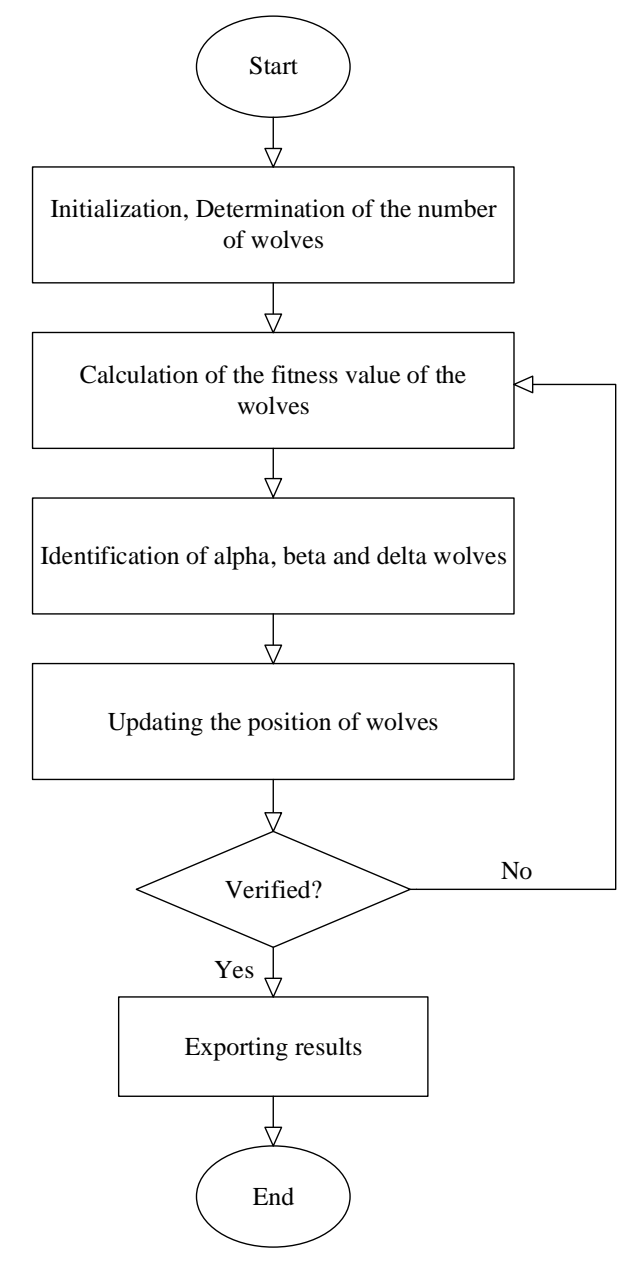

Figure 4. GWO algorithm 
In the present study, GWO [70] was employed for estimation of the parameters of Eq.1 to 8. The population number was selected to be 500 and the iteration number was determined to be 1000 according to different trial and error processes to reduce the cost function value. The cost function was defined as the mean square error between the target and estimated values according to Eq. 14 .

\section{Machine learning $(M L)$}

ML is regarded as a subset of AI. Using ML techniques, the computer learns to use patterns or "training samples" in data (processed information) to predict or make intelligent decisions without overt planning [71,72]. In other words, ML is the scientific study of algorithms and statistical models used by computer systems that use patterns and inference to perform tasks instead of using explicit instructions [73,74].

Time-series are data sequences collected over a period of time [75], which can be used as inputs to ML algorithms. This type of data reflects the changes that a phenomenon has undergone over time. Let $X^{t}$ be a time-series vector, in which $x_{t}$ is the outbreak at time point $t$ and $T$ is the set of all equidistant time points. To train ML methods effectively, we defined two scenarios, listed in Table 3.

Table 3. Input and output variables for training ML methods by time-series data

\begin{tabular}{|c|c|c|c|}
\hline & Inputs & Input number & Output \\
\hline Scenario 1 & $\mathrm{xt}_{\mathrm{t}-1}, \mathrm{xt}_{\mathrm{t}-7}, \mathrm{xt}_{\mathrm{t}-14}$, and $\mathrm{x}_{\mathrm{t}-21}$ & Four inputs & $\mathrm{xt}_{\mathrm{t}}$ (outbreak) \\
\hline Scenario 2 & $\mathrm{Xt}_{\mathrm{t}-1}, \mathrm{Xt}_{\mathrm{t}-2}, \mathrm{Xt}_{\mathrm{t}-3}, \mathrm{Xt}_{\mathrm{t}-4}$, and $\mathrm{X}_{\mathrm{t}-5}$ & Five inputs & $x_{t}$ (outbreak) \\
\hline
\end{tabular}

As can be seen in Table 3, scenario 1 employs data for three weeks to predict the outbreak on day $t$ and scenario 2 employs outbreak data for five days to predict the outbreak for day $t$. Both of these scenarios were employed for fitting the ML methods. In the present research, two frequently used ML methods, the multi-layered perceptron (MLP) and adaptive network-based fuzzy inference system (ANFIS) are employed for the prediction of the outbreak in the five countries.

\section{Multi-layered perceptron (MLP)}

ANN is an idea inspired by the biological nervous system, which processes information like the brain. The key element of this idea is the new structure of the information processing system [76-78]. The system is made up of several highly interconnected processing elements called neurons that work together to solve a problem $[78,79]$. ANNs, like humans, learn by example. The neural network is set up during a learning process to perform specific tasks, such as identifying patterns and categorizing information. In biological systems, learning is regulated by the synaptic connections between nerves. This method is also used in neural networks [80]. By processing experimental data, ANNs transfer knowledge or a law behind the data to the network structure, which is called learning. Basically, learning ability is the most important feature of such a smart system. A learning system is more flexible and easier to plan, so it can better respond to new issues and changes in processes [81].

In ANNs, with the help of programming knowledge, a data structure is designed that can act like a neuron. This data structure is called a node $[82,83]$. In this structure, the network between these nodes is trained by applying an educational algorithm to it. In this memory or neural network, the nodes have two active states (on or off) and one inactive state (off or 0 ), and each edge (synapse or connection between nodes) has a weight. Positive weights stimulate or activate the next inactive node, and negative weights inactivate or inhibit the next connected node (if active) [78,84]. In the ANN architecture, for the neural cell $c$, the input $b_{p}$ enters the cell from the previous cell $p$. $w_{p c}$ is the weight of the input $b_{p}$ with respect to cell $c$ and $a_{c}$ is the sum of the multiplications of the inputs and their weights [85]: 


$$
a_{c}=\sum w_{p c} b_{p c}
$$

A non-linear function $\Theta_{c}$ is applied to $a_{c}$. Accordingly, $b_{c}$ can be calculated as Eq. 20 [85]:

$$
b_{c}=\theta_{c}\left(a_{c}\right)
$$

Similarly, $w_{c n}$ is the weight of the $b_{c n}$ which is the output of $c$ to $n$. W is the collection of all the weights of the neural network in a set. For input $x$ and output $y, h_{w}(x)$ is the output of the neural network. The main goal is to learn these weights for reducing the error values between $y$ and $h_{w}(x)$. That is, the goal is to minimize the cost function $Q(W)$, Eq. 21 [85]:

$$
Q(W)=\frac{1}{2} \sum_{i=1}^{n}\left(y_{i}-o_{i}\right)^{2}
$$

In the present research, one of the frequently used types of ANN called the MLP [76] was employed to predict the outbreak. MLP was trained using a dataset related to both scenarios (according to Table 2). For the training of the network, 8, 12, and 16 inner neurons were tried to achieve the best response. Results were evaluated by RMSE and correlation coefficient to reduce the cost function value. Figure 5 presents the architecture of the MLP.

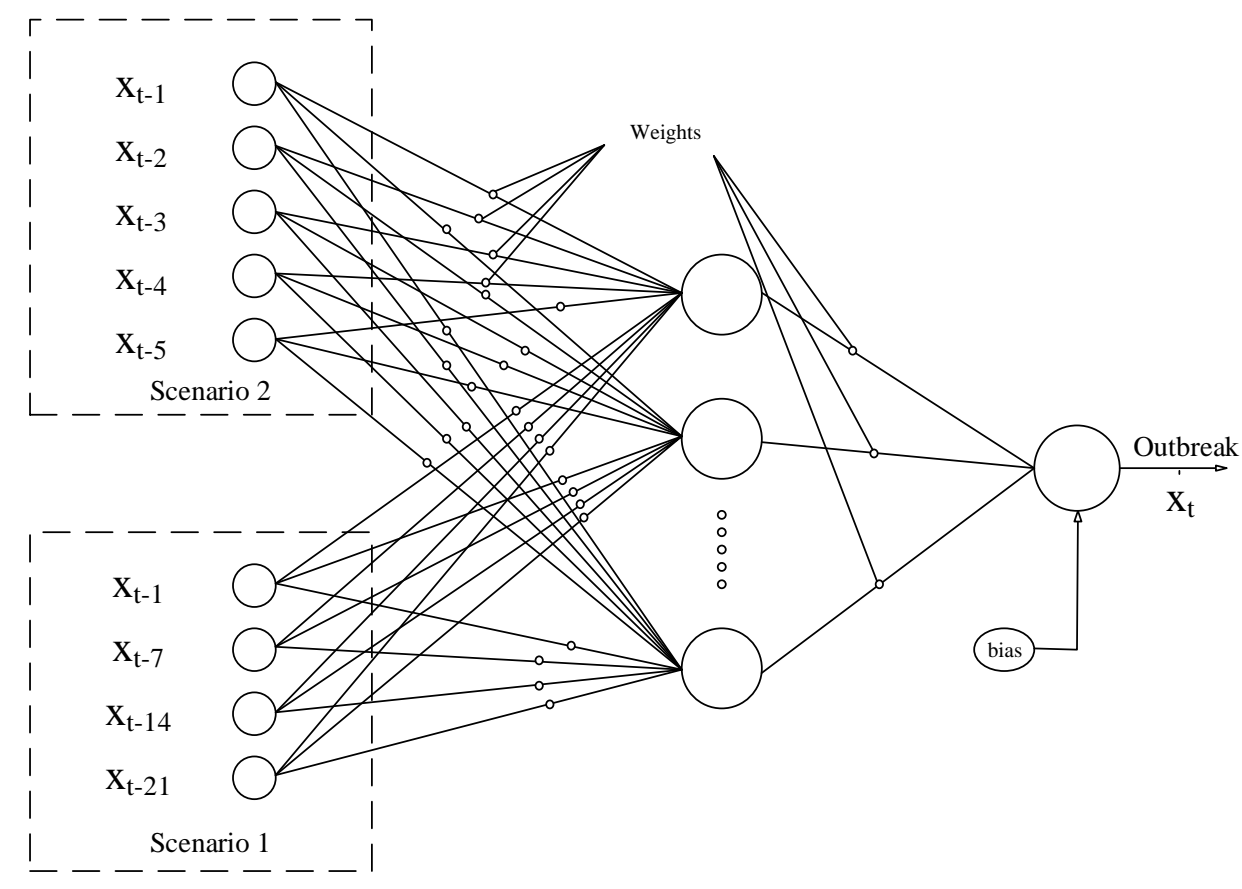

Figure 5. Architecture of MLP

\section{Adaptive neuro fuzzy inference system (ANFIS)}

An adaptive neuro fuzzy inference system is a type of ANN based on the Takagi-Sugeno fuzzy system [86]. This approach was developed in the early 1990s. Since this system integrates the concepts of neural networks and fuzzy logic, it can take advantage of both capabilities in a unified framework. This technique is one of the most frequently used and robust hybrid ML techniques. It is consistent with a set of fuzzy if-then rules that can be learned to approximate nonlinear functions $[87,88]$. Hence, ANFIS was proposed as a universal estimator. An important element of fuzzy systems is the fuzzy partition of the input space $[89,90]$. For input $k$, the fuzzy rules in the input space make a $k$ faces fuzzy cube. Achieving a flexible partition for nonlinear inversion is non-trivial. The idea of this model is to build a 
neural network whose outputs are a degree of the input that belongs to each class [91-93]. The membership functions (MFs) of this model can be nonlinear, multidimensional and, thus, different to conventional fuzzy systems [94-96]. In ANFIS, neural networks are used to increase the efficiency of fuzzy systems. The method used to design neural networks is to employ fuzzy systems or fuzzy-based structures. This model is a kind of division and conquest method. Instead of using one neural network for all the input and output data, several networks are created in this model:

- A fuzzy separator to cluster input-output data within multiple classes.

- A neural network for each class.

- Training neural networks with output input data in the corresponding classes.

Figure 6 presents a simple architecture for ANFIS.

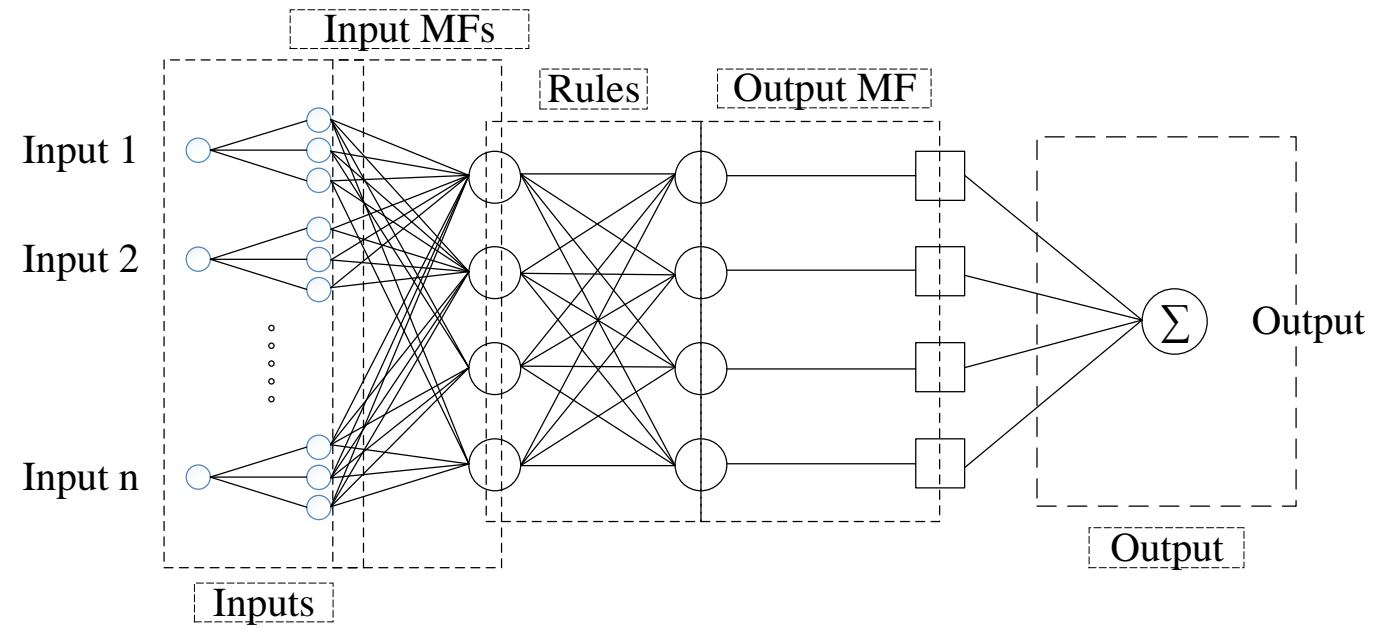

Figure 6. ANFIS architecture

In the present study, ANFIS is developed to tackle two scenarios described in table 3. Each input included by two MFs with the Tri. shape; Trap. shape and Gauss. shape MFs. The output MF type was selected to be linear with a hybrid optimizer type.

\section{Evaluation criteria}

Evaluation was conducted using the root mean square error (RMSE) and correlation coefficient. These statistics compare the target and output values and calculate a score as an index for the performance and accuracy of the developed methods [87,97]. Table 4 presents the evaluation criteria equations.

Table 4. Model Evaluation metrics

Accuracy and Performance Index
Correlation coefficient $=\frac{N \sum(A P)-\sum(A) \sum(P)}{\sqrt{\left[N \sum A^{2}-\left(\sum A\right)^{2}\right]\left[N \sum P^{2}-\left(\sum A P\right)^{2}\right]}}$
RMSE $=\sqrt{\frac{1}{N} \sum(A-P)^{2}}$

Where, $N$ is the number of data, $P$ and $A$ are, respectively, the predicted (output) and desired (target) values.

\section{Results}


Tables 5 to 12 present the results of the accuracy statistics for the logistic, linear, logarithmic, quadratic, cubic, compound, power and exponential equations, respectively. The coefficients of each equation were calculated by the three ML optimizers; GA, PSO and GWO. The table contains country name, model name, population size, number of iterations, processing time, RMSE and correlation coefficient.

Table 5. Accuracy statistics for the logistic model

\begin{tabular}{ccccccc}
\hline Country & Model & Pop. size & iteration & Processing time & RMSE & Correlation coefficient \\
\hline \multirow{5}{*}{ Italy } & GA & 300 & 500 & $82 \mathrm{~s}$ & 1028.98 & 0.996 \\
& PSO & 1000 & 500 & $36 \mathrm{~s}$ & 3358.1 & 0.997 \\
& GWO & 500 & 1000 & $14 \mathrm{~s}$ & 187.15 & 0.999 \\
\cline { 2 - 7 } China & GA & 300 & 500 & $79 \mathrm{~s}$ & 42160.4 & 0.982 \\
& PSO & 1000 & 500 & $35 \mathrm{~s}$ & 2524.44 & 0.994 \\
& GWO & 500 & 1000 & $13 \mathrm{~s}$ & 2270.58 & 0.995 \\
\cline { 2 - 7 } Iran & GA & 300 & 500 & $81 \mathrm{~s}$ & 1267.04 & 0.992 \\
& PSO & 1000 & 500 & $36 \mathrm{~s}$ & 628.62 & 0.997 \\
& GWO & 500 & 1000 & $13 \mathrm{~s}$ & 392.88 & 0.996 \\
\cline { 2 - 7 } USA & GA & 300 & 500 & $82 \mathrm{~s}$ & 1028.98 & 0.999 \\
& PSO & 1000 & 500 & $38 \mathrm{~s}$ & 350.33 & 0.999 \\
& GWO & 500 & 1000 & $15 \mathrm{~s}$ & 22.35 & 0.999 \\
\cline { 2 - 7 } Germany & GA & 300 & 500 & $86 \mathrm{~s}$ & 5339.5 & 0.983 \\
& PSO & 1000 & 500 & $39 \mathrm{~s}$ & 555.32 & 0.997 \\
& GWO & 500 & 1000 & $16 \mathrm{~s}$ & 55.54 & 0.999 \\
\hline
\end{tabular}

Table 6. Accuracy statistics for the linear model

\begin{tabular}{ccccccc}
\hline Country & Model & Pop. size & iteration & Processing time & RMSE & Correlation coefficient \\
\hline \multirow{5}{*}{ Italy } & GA & 300 & 500 & $92 \mathrm{~s}$ & 3774.06 & 0.845 \\
& PSO & 1000 & 500 & $42 \mathrm{~s}$ & 3645.76 & 0.844 \\
& GWO & 500 & 1000 & $16 \mathrm{~s}$ & 3642.44 & 0.844 \\
\cline { 2 - 7 } China & GA & 300 & 500 & $91 \mathrm{~s}$ & 7188.95 & 0.981 \\
& PSO & 1000 & 500 & $39 \mathrm{~s}$ & 6644.16 & 0.982 \\
& GWO & 500 & 1000 & $14 \mathrm{~s}$ & 5039.48 & 0.982 \\
\cline { 2 - 7 } Iran & GA & 300 & 500 & $96 \mathrm{~s}$ & 3330.45 & 0.943 \\
& PSO & 1000 & 500 & $45 \mathrm{~s}$ & 2072.71 & 0.944 \\
& GWO & 500 & 1000 & $18 \mathrm{~s}$ & 1981.97 & 0.944 \\
\cline { 2 - 7 } USA & GA & 300 & 500 & $88 \mathrm{~s}$ & 850.22 & 0.745 \\
& PSO & 1000 & 500 & $40 \mathrm{~s}$ & 596.69 & 0.746 \\
& GWO & 500 & 1000 & $17 \mathrm{~s}$ & 592.48 & 0.746 \\
\cline { 2 - 7 } Germany & GA & 300 & 500 & $93 \mathrm{~s}$ & 1118.77 & 0.758 \\
& PSO & 1000 & 500 & $47 \mathrm{~s}$ & 964.46 & 0.759 \\
& GWO & 500 & 1000 & $20 \mathrm{~s}$ & 951.63 & 0.759 \\
\hline
\end{tabular}

Table 7. Accuracy statistics for the logarithmic model 


\begin{tabular}{|c|c|c|c|c|c|c|}
\hline & Model & Pop. size & iteration & $\begin{array}{c}\text { Processing } \\
\text { time }\end{array}$ & RMSE & Correlation coefficient \\
\hline \multirow{3}{*}{ Italy } & GA & 300 & 500 & $98 \mathrm{~s}$ & 8325.33 & 0.634 \\
\hline & PSO & 1000 & 500 & $51 \mathrm{~s}$ & 8818.2 & 0.634 \\
\hline & GWO & 500 & 1000 & $20 \mathrm{~s}$ & 9296.59 & 0.634 \\
\hline \multirow{3}{*}{ China } & GA & 300 & 500 & $96 \mathrm{~s}$ & 40828.2 & 0.847 \\
\hline & PSO & 1000 & 500 & $42 \mathrm{~s}$ & 43835.37 & 0.847 \\
\hline & GWO & 500 & 1000 & $17 \mathrm{~s}$ & 42714.93 & 0.847 \\
\hline \multirow{3}{*}{ Iran } & GA & 300 & 500 & $102 \mathrm{~s}$ & 4929.97 & 0.757 \\
\hline & PSO & 1000 & 500 & $59 \mathrm{~s}$ & 8775.56 & 0.757 \\
\hline & GWO & 500 & 1000 & $22 \mathrm{~s}$ & 8995.52 & 0.756 \\
\hline \multirow{3}{*}{ USA } & GA & 300 & 500 & $94 \mathrm{~s}$ & 889.15 & 0.538 \\
\hline & PSO & 1000 & 500 & $37 \mathrm{~s}$ & 1130.33 & 0.538 \\
\hline & GWO & 500 & 1000 & $15 \mathrm{~s}$ & 1135.12 & 0.538 \\
\hline \multirow{3}{*}{$\begin{array}{c}\text { Germa } \\
\text { ny }\end{array}$} & GA & 300 & 500 & $95 \mathrm{~s}$ & 1552.22 & 0.548 \\
\hline & PSO & 1000 & 500 & $45 \mathrm{~s}$ & 1966.81 & 0.548 \\
\hline & GWO & 500 & 1000 & $21 \mathrm{~s}$ & 1878.67 & 0.548 \\
\hline
\end{tabular}

Table 8. Accuracy statistics for the quadratic model

\begin{tabular}{ccccccc}
\hline & Model & Pop. size & iteration & Processing time & RMSE & Correlation coefficient \\
\hline \multirow{6}{*}{ Italy } & GA & 300 & 500 & $102 \mathrm{~s}$ & 6710.01 & 0.976 \\
& PSO & 1000 & 500 & $54 \mathrm{~s}$ & 5102.4 & 0.953 \\
& GWO & 500 & 1000 & $26 \mathrm{~s}$ & 1272.1 & 0.982 \\
\hline \multirow{4}{*}{ China } & GA & 300 & 500 & $100 \mathrm{~s}$ & 7921.33 & 0.992 \\
& PSO & 1000 & 500 & $46 \mathrm{~s}$ & 4328.71 & 0.993 \\
& GWO & 500 & 1000 & $20 \mathrm{~s}$ & 3710.16 & 0.993 \\
\hline \multirow{6}{*}{ Iran } & GA & 300 & 500 & $105 \mathrm{~s}$ & 6771.74 & 0.995 \\
& PSO & 1000 & 500 & $62 \mathrm{~s}$ & 822.09 & 0.998 \\
& GWO & 500 & 1000 & $24 \mathrm{~s}$ & 310.02 & 0.998 \\
\hline \multirow{6}{*}{ USA } & GA & 300 & 500 & $98 \mathrm{~s}$ & 754.6 & 0.931 \\
& PSO & 1000 & 500 & $38 \mathrm{~s}$ & 791.92 & 0.853 \\
& GWO & 500 & 1000 & $19 \mathrm{~s}$ & 307.58 & 0.938 \\
\hline \multirow{6}{*}{ Germany } & GA & 300 & 500 & $101 \mathrm{~s}$ & 7577 & 0.904 \\
& PSO & 1000 & 500 & $49 \mathrm{~s}$ & 752.95 & 0.923 \\
& GWO & 500 & 1000 & $26 \mathrm{~s}$ & 472.62 & 0.946 \\
\hline
\end{tabular}

Table 9. Accuracy statistics for the cubic model

\begin{tabular}{ccccccc}
\hline \multirow{6}{*}{ Italy } & Model & Pop. size & iteration & Processing time & RMSE & Correlation coefficient \\
\hline \multirow{6}{*}{ China } & GA & 300 & 500 & $112 \mathrm{~s}$ & 7973.11 & 0.993 \\
& PSO & 1000 & 500 & $61 \mathrm{~s}$ & 4827.08 & 0.996 \\
& GWO & 500 & 1000 & $34 \mathrm{~s}$ & 324.33 & 0.998 \\
\cline { 2 - 7 } & GA & 300 & 500 & $113 \mathrm{~s}$ & 15697.84 & 0.971 \\
& PSO & 1000 & 500 & $59 \mathrm{~s}$ & 3611.15 & 0.995 \\
& GWO & 500 & 1000 & $34 \mathrm{~s}$ & 2429.45 & 0.995 \\
\cline { 2 - 7 }
\end{tabular}




\begin{tabular}{ccccccc}
\cline { 2 - 7 } Iran & GA & 300 & 500 & $120 \mathrm{~s}$ & 5852.66 & 0.995 \\
& PSO & 1000 & 500 & $88 \mathrm{~s}$ & 3809.76 & 0.997 \\
& GWO & 500 & 1000 & $39 \mathrm{~s}$ & 250.2 & 0.999 \\
\cline { 2 - 7 } USA & GA & 300 & 500 & $110 \mathrm{~s}$ & 37766.56 & 0.875 \\
& PSO & 1000 & 500 & $49 \mathrm{~s}$ & 678.36 & 0.979 \\
& GWO & 500 & 1000 & $25 \mathrm{~s}$ & 118.24 & 0.991 \\
\cline { 2 - 7 } Germany & GA & 300 & 500 & $116 \mathrm{~s}$ & 1709.06 & 0.744 \\
& PSO & 1000 & 500 & $59 \mathrm{~s}$ & 1812.78 & 0.967 \\
& GWO & 500 & 1000 & $29 \mathrm{~s}$ & 196.8 & 0.99 \\
\hline
\end{tabular}

Table 10. Accuracy statistics for the compound model

\begin{tabular}{ccccccc}
\hline \multirow{5}{*}{ Italy } & Model & $\begin{array}{c}\text { Pop. } \\
\text { size }\end{array}$ & iteration & $\begin{array}{c}\text { Processing } \\
\text { time }\end{array}$ & RMSE & $\begin{array}{c}\text { Correlation } \\
\text { coefficient }\end{array}$ \\
\hline \multirow{6}{*}{ China } & GA & 300 & 500 & $92 \mathrm{~s}$ & 8347.51 & 0.912 \\
& PSO & 1000 & 500 & $53 \mathrm{~s}$ & 195705.52 & 0.918 \\
& GWO & 500 & 1000 & $22 \mathrm{~s}$ & 12585.79 & 0.951 \\
\cline { 2 - 7 } & GA & 300 & 500 & $90 \mathrm{~s}$ & 41544.05 & 0.986 \\
& PSO & 1000 & 500 & $48 \mathrm{~s}$ & 40195.9 & 0.988 \\
& GWO & 500 & 1000 & $23 \mathrm{~s}$ & 24987.34 & 0.895 \\
\cline { 2 - 7 } Iran & GA & 300 & 500 & $99 \mathrm{~s}$ & 1487501.93 & 0.782 \\
& PSO & 1000 & 500 & $81 \mathrm{~s}$ & 8216.81 & 0.986 \\
& GWO & 500 & 1000 & $26 \mathrm{~s}$ & 13635.01 & 0.864 \\
\cline { 2 - 7 } USA & GA & 300 & 500 & $96 \mathrm{~s}$ & 655.62 & 0.994 \\
& PSO & 1000 & 500 & $32 \mathrm{~s}$ & 1026.03 & 0.827 \\
& GWO & 500 & 1000 & $16 \mathrm{~s}$ & 364.87 & 0.988 \\
\hline \multirow{5}{*}{ Germany } & GA & 300 & 500 & $98 \mathrm{~s}$ & 15333537.7 & 0.93 \\
& PSO & 1000 & 500 & $72 \mathrm{~s}$ & 1557.23 & 0.976 \\
& GWO & 500 & 1000 & $20 \mathrm{~s}$ & 431.97 & 0.998 \\
\hline
\end{tabular}

Table 11. Accuracy statistics for the power model

\begin{tabular}{|c|c|c|c|c|c|c|}
\hline & Model & $\begin{array}{l}\text { Pop. } \\
\text { size }\end{array}$ & iteration & $\begin{array}{c}\text { Processing } \\
\text { time }\end{array}$ & RMSE & $\begin{array}{l}\text { Correlation } \\
\text { coefficient }\end{array}$ \\
\hline \multirow{3}{*}{ Italy } & GA & 300 & 500 & $72 \mathrm{~s}$ & 7063.4 & 0.983 \\
\hline & PSO & 1000 & 500 & $40 \mathrm{~s}$ & 6150.52 & 0.982 \\
\hline & GWO & 500 & 1000 & $13 \mathrm{~s}$ & 3450.96 & 0.991 \\
\hline \multirow{3}{*}{ China } & GA & 300 & 500 & $65 \mathrm{~s}$ & 39669.92 & 0.976 \\
\hline & PSO & 1000 & 500 & $39 \mathrm{~s}$ & 19365.58 & 0.987 \\
\hline & GWO & 500 & 1000 & $12 \mathrm{~s}$ & 4078.99 & 0.989 \\
\hline \multirow{3}{*}{ Iran } & GA & 300 & 500 & $83 \mathrm{~s}$ & 2343032.5 & 0.951 \\
\hline & PSO & 1000 & 500 & $65 \mathrm{~s}$ & 92755.53 & 0.975 \\
\hline & GWO & 500 & 1000 & $15 \mathrm{~s}$ & 1031.6 & 0.991 \\
\hline \multirow{3}{*}{ USA } & GA & 300 & 500 & $79 \mathrm{~s}$ & 1030.01 & 0.779 \\
\hline & PSO & 1000 & 500 & $24 \mathrm{~s}$ & 1005.27 & 0.751 \\
\hline & GWO & 500 & 1000 & $11 \mathrm{~s}$ & 790.16 & 0.837 \\
\hline Germany & GA & 300 & 500 & $85 \mathrm{~s}$ & 1475.39 & 0.871 \\
\hline
\end{tabular}




\begin{tabular}{cccccc} 
PSO & 1000 & 500 & $69 \mathrm{~s}$ & 1387.94 & 0.916 \\
GWO & 500 & 1000 & $14 \mathrm{~s}$ & 1341.91 & 0.875 \\
\hline
\end{tabular}

Table 12. Accuracy statistics for the exponential model

\begin{tabular}{|c|c|c|c|c|c|c|}
\hline & Model & $\begin{array}{l}\text { Pop. } \\
\text { size }\end{array}$ & iteration & $\begin{array}{c}\text { Processing } \\
\text { time }\end{array}$ & RMSE & $\begin{array}{l}\text { Correlation } \\
\text { coefficient }\end{array}$ \\
\hline \multirow{3}{*}{ Italy } & GA & 300 & 500 & $79 \mathrm{~s}$ & 8163.1 & 0.995 \\
\hline & PSO & 1000 & 500 & $48 \mathrm{~s}$ & 52075925.37 & 0.839 \\
\hline & GWO & 500 & 1000 & $18 \mathrm{~s}$ & 12585.79 & 0.951 \\
\hline \multirow{3}{*}{ China } & GA & 300 & 500 & $71 \mathrm{~s}$ & 68991.73 & 0.866 \\
\hline & PSO & 1000 & 500 & $45 \mathrm{~s}$ & 80104.27 & 0.865 \\
\hline & GWO & 500 & 1000 & $17 \mathrm{~s}$ & 24987.34 & 0.895 \\
\hline \multirow{3}{*}{ Iran } & GA & 300 & 500 & $89 \mathrm{~s}$ & 1436025.84 & 0.767 \\
\hline & PSO & 1000 & 500 & $70 \mathrm{~s}$ & 3745673.26 & 0.744 \\
\hline & GWO & 500 & 1000 & $21 \mathrm{~s}$ & 13635.01 & 0.864 \\
\hline \multirow{3}{*}{ USA } & GA & 300 & 500 & $84 \mathrm{~s}$ & 457051.4 & 0.974 \\
\hline & PSO & 1000 & 500 & $30 \mathrm{~s}$ & 982.37 & 0.932 \\
\hline & GWO & 500 & 1000 & $15 \mathrm{~s}$ & 364.87 & 0.988 \\
\hline \multirow{3}{*}{ Germany } & GA & 300 & 500 & $87 \mathrm{~s}$ & 8176.54 & 0.981 \\
\hline & PSO & 1000 & 500 & $74 \mathrm{~s}$ & 3278.55 & 0.998 \\
\hline & GWO & 500 & 1000 & $19 \mathrm{~s}$ & 431.97 & 0.998 \\
\hline
\end{tabular}

According to Tables 5 to 12, GWO provided the highest accuracy (smallest RMSE and largest correlation coefficient) and smallest processing time compared to PSO and GA for fitting the logistic, linear, logarithmic, quadratic, cubic, power, compound, and exponential-based equations for all five countries. It can be suggested that GWO is a sustainable optimizer due to its acceptable processing time compared with PSO and GA. Therefore, GWO was selected as the best optimizer by providing the highest accuracy values compared with PSO and GA. In general, it can be claimed that GWO, by suggesting the best parameter values for the functions presented in Table 2, increases outbreak prediction accuracy for COVID-19 in comparison with PSO and GA. Therefore, the functions derived by GWO were selected as the best predictors for this research.

Tables 13 to 17 present the description and coefficients of the linear, logarithmic, quadratic, cubic, compound, power, exponential and logistic equations estimated by GWO. Tables 13 to 17 also present the RMSE and $r$-square values for each equation fitted to data for China, Italy, Iran, Germany and USA, respectively.

Table 13. Model description for China fitted by GWO

\begin{tabular}{clcc}
\hline $\begin{array}{c}\text { Model } \\
\text { name }\end{array}$ & \multicolumn{1}{c}{ Description } & RMSE & $\begin{array}{c}\text { r- } \\
\text { square }\end{array}$ \\
\hline Linear & $\mathrm{R}=3036,4 \times \mathrm{x}-13509,84$ & 5039.48 & 0.964 \\
Logarithmic & $\mathrm{R}=-33948,15+27124,70 \times \log (\mathrm{x})$ & 42714.93 & 0.718 \\
Quadratic & $\mathrm{R}=-5080,88+1455,98 \times \mathrm{x}+50,98 \times \mathrm{x}^{2}$ & 3710.16 & 0.98 \\
Cubic & $\mathrm{R}=3984,73-1790,2 \times \mathrm{x}+308,52 \times \mathrm{x}^{2}-5,53 \times \mathrm{x}^{3}$ & 2429.45 & 0.99
\end{tabular}




\begin{tabular}{clrc} 
Compound & $\mathrm{R}=1601,03 \times 1.16^{\mathrm{x}}$ & 24987.34 & 0.801 \\
Power & $\mathrm{R}=262,27 \times \mathrm{x}^{1,69}$ & 4078.99 & 0.98 \\
Exponential & $\mathrm{R}=1601,03 \times \operatorname{EXP}(0,15 \times \mathrm{x})$ & 24987.34 & 0.801 \\
Logistic & $\mathrm{R}=85011,297 /(1+\operatorname{EXP}(((4 \times 4483,304) *(9,423$ & 2270.58 & 0.992 \\
\hline
\end{tabular}

Table 14. Model description for Italy fitted by GWO

\begin{tabular}{|c|c|c|c|}
\hline Model name & Description & RMSE & $\begin{array}{c}\text { r- } \\
\text { square }\end{array}$ \\
\hline Linear & $R=663,71 \times x-5437,25$ & 3642.44 & 0.713 \\
\hline Logarithmic & $R=-7997,93+5162,83 \times \log (x)$ & 9296.59 & 0.402 \\
\hline Quadratic & $R=2998,21-917,93 \times x+51,02 \times x^{2}$ & 1272.1 & 0.965 \\
\hline Cubic & $\begin{array}{c}\mathrm{R}=-978,55+506,05 \times \mathrm{B} 2-61,95 \times \mathrm{x}^{2} \\
+2,42 \times \mathrm{x}^{3}\end{array}$ & 324.33 & 0.997 \\
\hline Compound & $\mathrm{R}=2,78 \times 1,406^{\mathrm{x}}$ & 12585.79 & 0.904 \\
\hline Power & $\mathrm{R}=0,096 \times \mathrm{x}^{3,476}$ & 3450.96 & 0.984 \\
\hline Exponential & $\mathrm{R}=2,786 \times \operatorname{EXP}(0,341 \times \mathrm{x})$ & 12585.79 & 0.904 \\
\hline Logistic & $\begin{aligned} \mathrm{R}=70731,084 / & (1+\operatorname{EXP}(((4 \times 3962,88) \\
& \times(23,88-\mathrm{x}) / 70731,08) \\
& +2))\end{aligned}$ & 187.15 & 0.999 \\
\hline
\end{tabular}

Table 15. Model description for Iran fitted by GWO

\begin{tabular}{|c|c|c|c|c|}
\hline $\begin{array}{c}\text { Model } \\
\text { name }\end{array}$ & & Description & RMSE & r-square \\
\hline Linear & $\mathrm{R}=$ & $656,068 \times x-4527,69$ & 1981.97 & 0.891 \\
\hline Logarithmic & $\mathrm{R}=$ & $-7921,009+5449,784 \times \log (x)$ & 8995.52 & 0.574 \\
\hline Quadratic & $\mathrm{R}=$ & $310,48-251,09 \times x+29,26 \times x^{2}$ & 310.027 & 0.997 \\
\hline Cubic & $\mathrm{R}=$ & $\begin{array}{c}902,33-463,02 \times x+46,07 \times x^{2}-0,36 \\
\times x^{3}\end{array}$ & 250.204 & 0.998 \\
\hline Compound & $\mathrm{R}=$ & $13,26 \times 1,33^{\mathrm{x}}$ & 13635.014 & 0.748 \\
\hline Power & $\mathrm{R}=$ & $0,51 \times x^{3,09}$ & 1031.607 & 0.982 \\
\hline
\end{tabular}




\begin{tabular}{|c|c|c|c|}
\hline Exponential & $\mathrm{R}=$ & $13,26 \times \operatorname{EXP}(0,28 \times x)$ & 13635.014 \\
\hline Logistic & $\mathrm{R}=$ & $\begin{aligned} & 21936,052 /(1+\operatorname{EXP}(((4 * 1255,36) \\
&\times(14,66-x) / 21936,052)+2))\end{aligned}$ & 392.88 \\
\hline
\end{tabular}

Table 16. Model description for Germany fitted by GWO

\begin{tabular}{clrc}
\hline $\begin{array}{c}\text { Model } \\
\text { name }\end{array}$ & \multicolumn{1}{c}{ Description } & RMSE & $\begin{array}{c}\text { r- } \\
\text { square }\end{array}$ \\
\hline Linear & $\mathrm{R}=128,421 \times \mathrm{x}-1130,294$ & 951.635 & 0.577 \\
Logarithmic & $\mathrm{R}=-1528,684+959,941 \times \log (\mathrm{x})$ & 1878.672 & 0.3 \\
Quadratic & $\mathrm{R}=911,113-254,342 \times \mathrm{x}+12,347 \times \mathrm{x}^{2}$ & 472.624 & 0.895 \\
Cubic & $\mathrm{R}=-478,087+243,097 \times \mathrm{x}-27,118 \times \mathrm{x}^{2}+0,848 \times \mathrm{x}^{3}$ & 196.809 & 0.981 \\
Compound & $\mathrm{R}=3,821 \times 1,263^{\mathrm{x}}$ & 431.975 & 0.996 \\
Power & $\mathrm{R}=0,937 \mathrm{x}^{2,021}$ & 1341.911 & 0.766 \\
Exponential & $\mathrm{R}=3,821 \times \operatorname{EXP}(0,233 \times \mathrm{x})$ & 431.975 & 0.996 \\
Logistic & $\mathrm{R}=55179,669 /(1+\operatorname{EXP}(((4 \times 3740,457) \times(30,49$ & 55.546 & 0.998 \\
& $-\mathrm{x}) / 55179,669)+2))$ & & \\
\hline
\end{tabular}

Table 17. Model description for USA fitted by GWO

\begin{tabular}{clcc}
\hline $\begin{array}{c}\text { Model } \\
\text { name }\end{array}$ & \multicolumn{1}{c}{ Description } & RMSE & r-square \\
\hline Linear & $\mathrm{R}=76,833 \times \mathrm{x}-666,79$ & 592.486 & 0.557 \\
Logarithmic & $\mathrm{R}=-902,637+573,32 \times \log (\mathrm{x})$ & 1135.124 & 0.289 \\
Quadratic & $\mathrm{R}=584,76-157,831 \times \mathrm{x}+7,569 \times \mathrm{x}^{2}$ & 307.585 & 0.88 \\
Cubic & $\mathrm{R}=-333,235+170,881 \times \mathrm{x}-18,509 \times \mathrm{x}^{2}+0,56 \times \mathrm{x}^{3}$ & 118.247 & 0.982 \\
Compound & $\mathrm{R}=6,296 \times 1,214^{\mathrm{x}}$ & 364.875 & 0.977 \\
Power & $\mathrm{R}=1,707 \times \mathrm{x}^{1,735}$ & 790.163 & 0.702 \\
Exponential & $\mathrm{R}=6,296 \times \mathrm{EXP}(0,194 \times \mathrm{x})$ & 364.875 & 0.977 \\
Logistic & $\mathrm{R}=32604,552 /(1+\mathrm{EXP}(((4 \times 2288,932) \times(30,303$ & 22.354 & 0.999 \\
\hline
\end{tabular}

As is clear from Tables 13 to 17, in general, the logistic equation followed by the quadratic and cubic equations provided the smallest RMSE and the largest $r$-square values for the prediction of 
COVID-19 outbreak. The claim can also be considered from Figure 7 to 11, which presents the capability and trend of each model derived by GWO in the prediction of COVID-19 cases for China, Italy, Iran, Germany, and the USA, respectively.

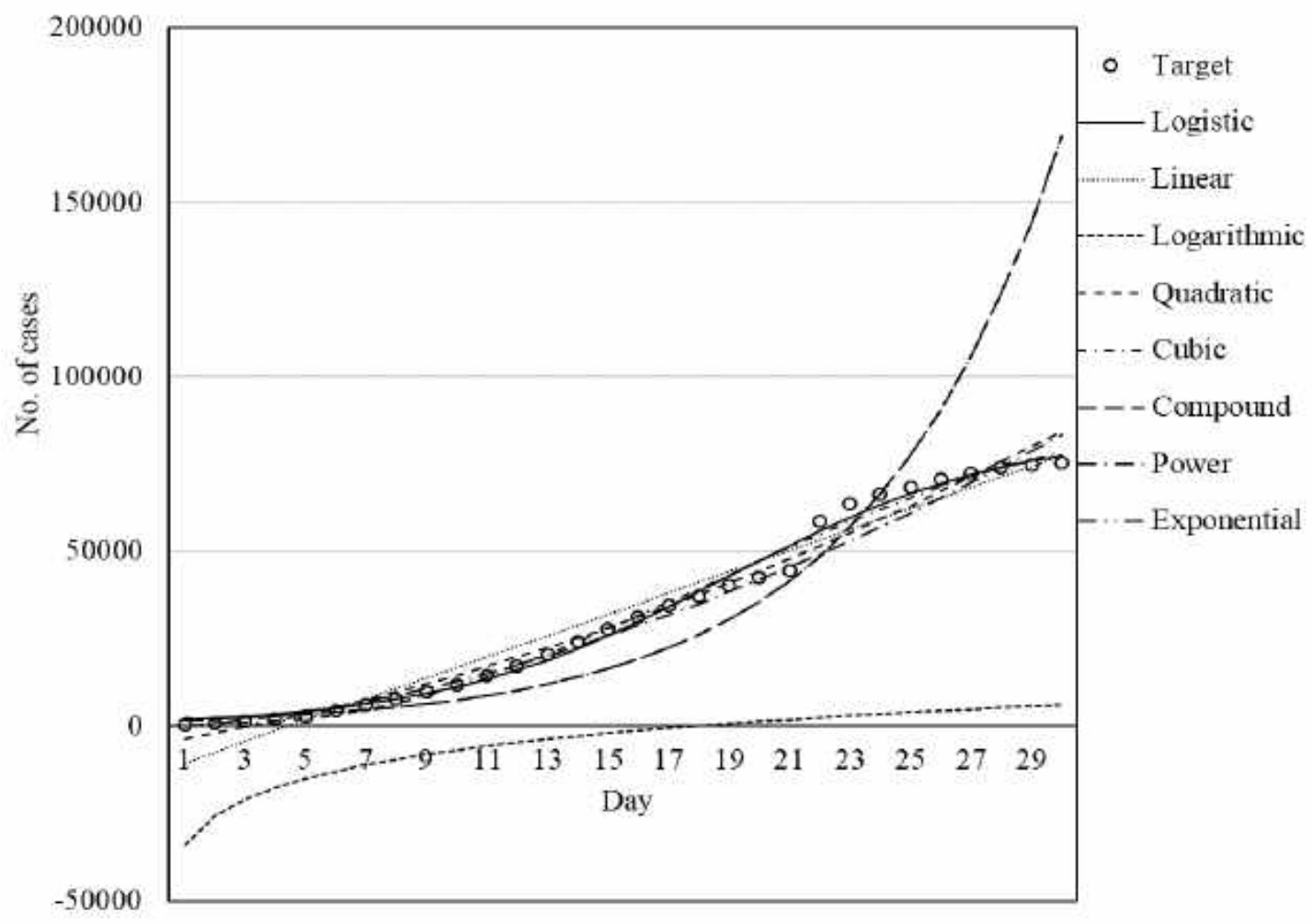

Figure 7. Fitness graph for China fitted by GWO

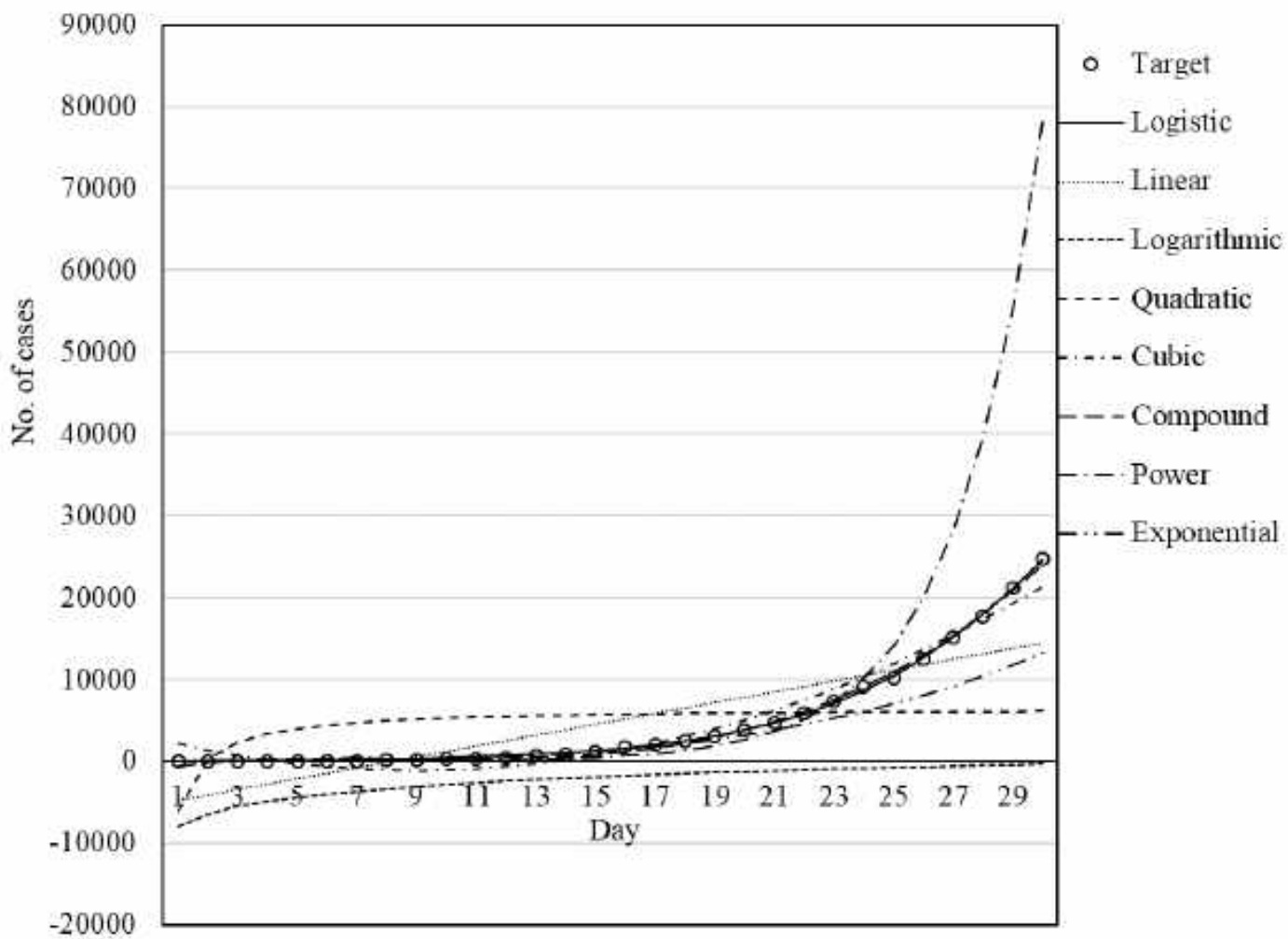


Figure 8. Set of models for Italy fitted by GWO

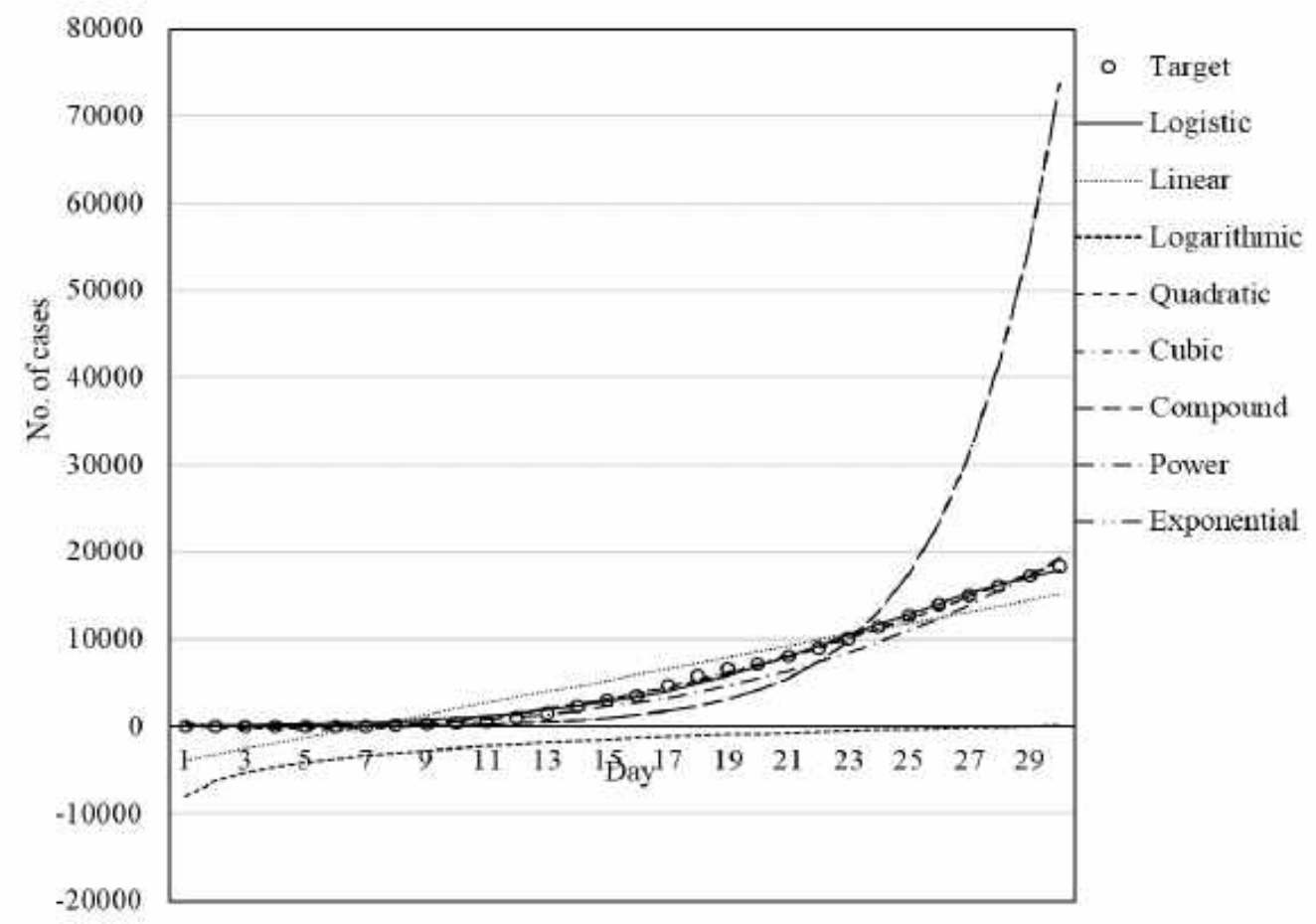

Figure 9. Set of models for Iran fitted by GWO

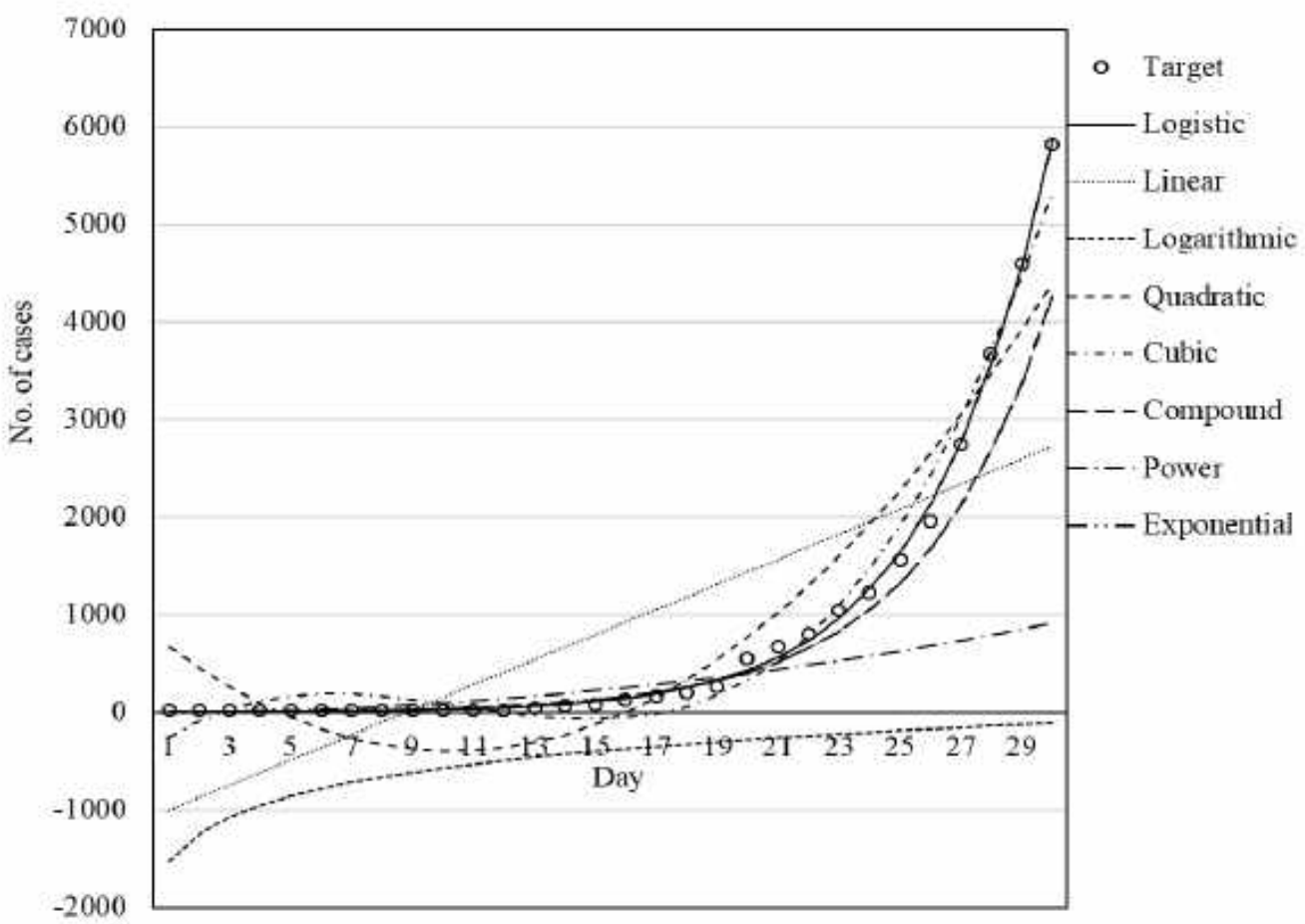

Figure 10. Set of models for Germany fitted by GWO 


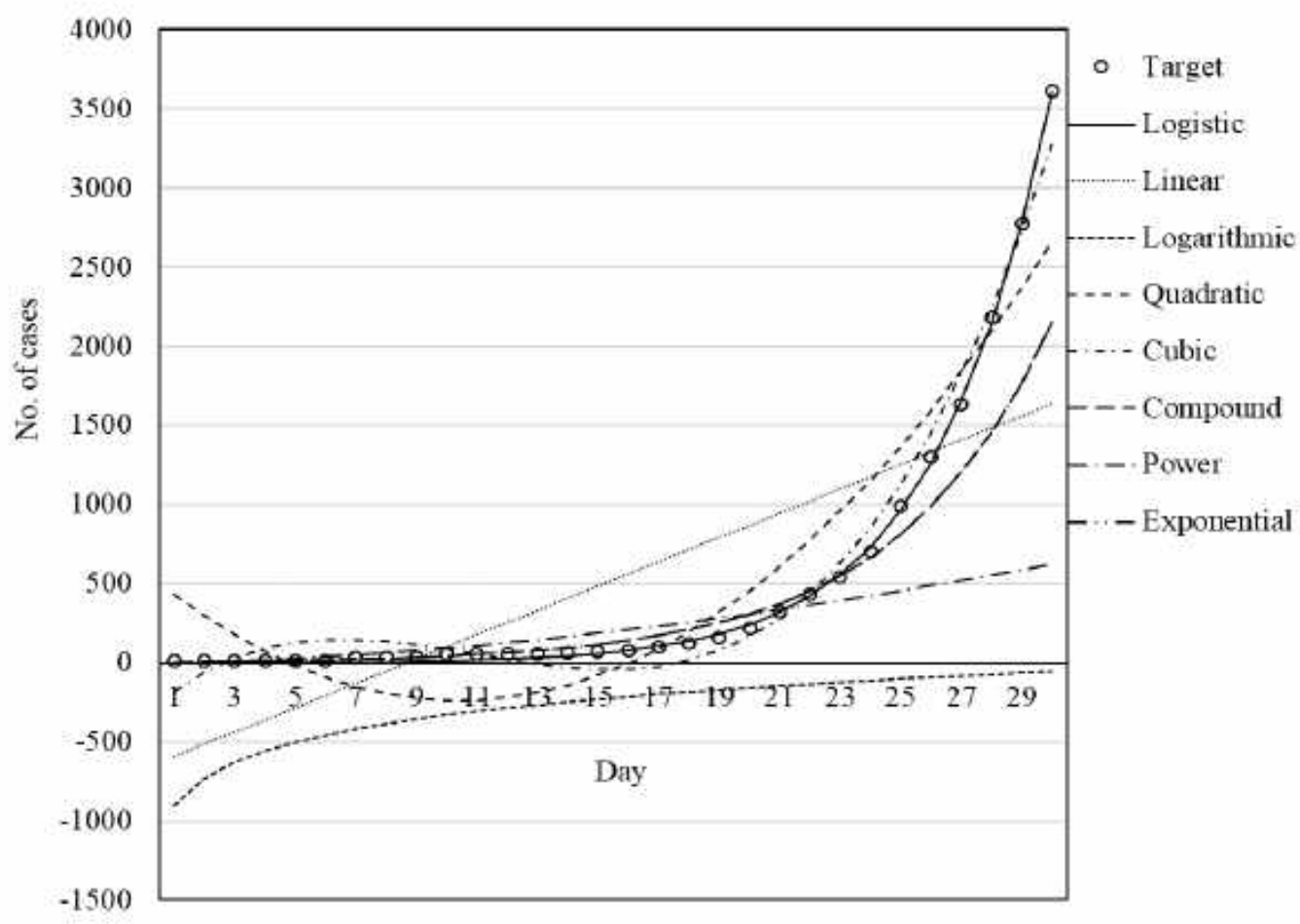

Figure 11. Set of models for USA fitted by GWO

Figures 7 to 11 illustrate the fit of the models investigated in this paper. The best fit for the prediction of COVID-19 cases was achieved for the logistic model followed by cubic and quadratic models for China (Figure 7), logistic followed by cubic models for Italy (Figure 8), cubic followed by logistic and quadratic models for Iran (Figure 9), the logistic model for Germany (Figure 10), and logistic model for the USA (Figure 11).

\section{Machine learning results}

This section presents the results for the training stage of ML methods. MLP and ANFIS were employed as single and hybrid ML methods, respectively. ML methods were trained using two datasets related to scenario 1 and scenario 2 . Table 14 presents the results of the training phase.

Table 18. Results for the training phase of the ML methods

\begin{tabular}{|c|c|c|c|c|c|c|c|c|c|c|c|c|}
\hline & \multicolumn{6}{|c|}{ Scenario 1} & \multicolumn{6}{|c|}{ Scenario2 } \\
\hline & \multicolumn{3}{|c|}{ MLP } & \multicolumn{3}{|c|}{ ANFIS } & \multicolumn{4}{|c|}{ MLP } & \multicolumn{2}{|c|}{ ANFIS } \\
\hline & $\begin{array}{c}\text { No. of } \\
\text { neurons }\end{array}$ & $\mathrm{r}$ & RMSE & $\begin{array}{l}\text { MF } \\
\text { type }\end{array}$ & $\mathrm{r}$ & RMSE & $\begin{array}{c}\text { No. of } \\
\text { neurons }\end{array}$ & $\mathrm{r}$ & RMSE & $\begin{array}{l}\text { MF } \\
\text { type }\end{array}$ & $\mathrm{r}$ & RMSE \\
\hline \multirow{3}{*}{ Italy } & 8 & 0.999 & 190.81 & Tri. & 0.999 & 189.76 & 8 & 0.999 & 199.52 & Tri. & 0.999 & 188.55 \\
\hline & 12 & 0.999 & 194.84 & Trap. & $\begin{array}{c}0 \\
.841\end{array}$ & 3743.63 & 12 & 0.999 & 195.79 & Trap. & 0.876 & 3276 \\
\hline & 16 & 0.999 & 188.18 & Gauss & 0.998 & 320.93 & 16 & 0.999 & 195.2 & Gauss & 0.999 & 206.66 \\
\hline \multicolumn{2}{|c|}{ Average } & 0.999 & 191.27 & & 0.946 & 1418.1 & Average & 0.999 & 196.83 & & 0.958 & 1223.73 \\
\hline China & 8 & 0.995 & 2287.55 & Tri. & 0.996 & 2293.09 & 8 & 0.996 & 2265.95 & Tri. & 0.996 & 2272.13 \\
\hline
\end{tabular}




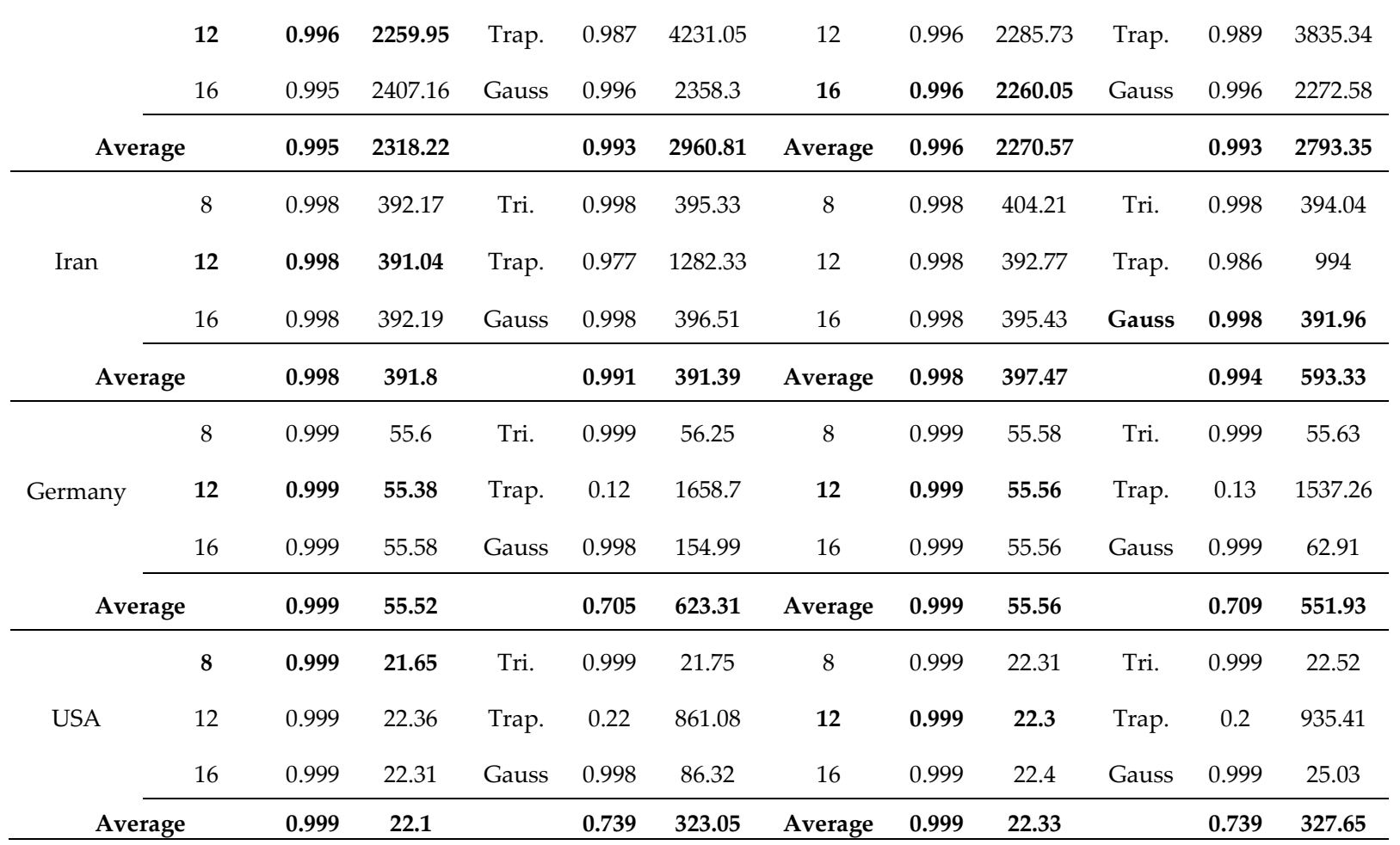

According to Table 18, the dataset related to scenarios 1 and 2 have different performance values. Accordingly, for Italy, the MLP with 16 neurons provided the highest accuracy for scenario 1 and ANFIS with tri. MF provided the highest accuracy for scenario 2. By considering the average values of the RMSE and correlation coefficient, it can be concluded that scenario 1 is more suitable for modeling outbreak cases in Italy, as it provides a higher accuracy (the smallest RMSE and the largest correlation coefficient) than scenario 2.

For the dataset related to China, for both scenarios, MLP with 12 and 16 neurons, respectively for scenarios 1 and 2, provided the highest accuracy compared with the ANFIS model. By considering the average values of RMSE and correlation coefficient, it can be concluded that scenario 2 with a larger average correlation coefficient and smaller average RMSE than scenario 1 is more suitable for modeling the outbreak in China.

For the dataset of Iran, MLP with 12 neurons in the hidden layer for scenario 1 and ANFIS with Gaussian MF type for scenario 2 provided the best performance for the prediction of the outbreak. By considering the average values of the RMSE and correlation coefficient, it can be concluded that scenario 1 provided better performance than scenario 2. Also, in general, the MLP has higher prediction accuracy compared with the ANFIS method.

In Germany, MLP with 12 neurons in its hidden layer provided the highest accuracy (smallest RMSE and largest correlation coefficient). By considering the average values of the RMSE and correlation coefficient, it can be concluded that scenario 1 is more suitable for the prediction of the outbreak in Germany than scenario 2.

In the USA, the MLP with 8 and 12 neurons, respectively, for scenarios 1 and 2, provided higher accuracy (the smallest RMSE and the largest correlation coefficient values) than the ANFIS model. By considering the average values of the RMSE and correlation coefficient values, it can be concluded that scenario 1 is more suitable than scenario 2, and MLP is more suitable than ANFIS for outbreak prediction.

Figures 12 to 16 present the model fits for Italy, China, Iran, Germany, and the USA, respectively. By comparing Figure 12 to 16 with Figures 7 to 11, it can be concluded that the MLP and the logistic model fitted by GWO provided a better fit than the other models. In addition, the ML methods provided better performance compared with other models. 


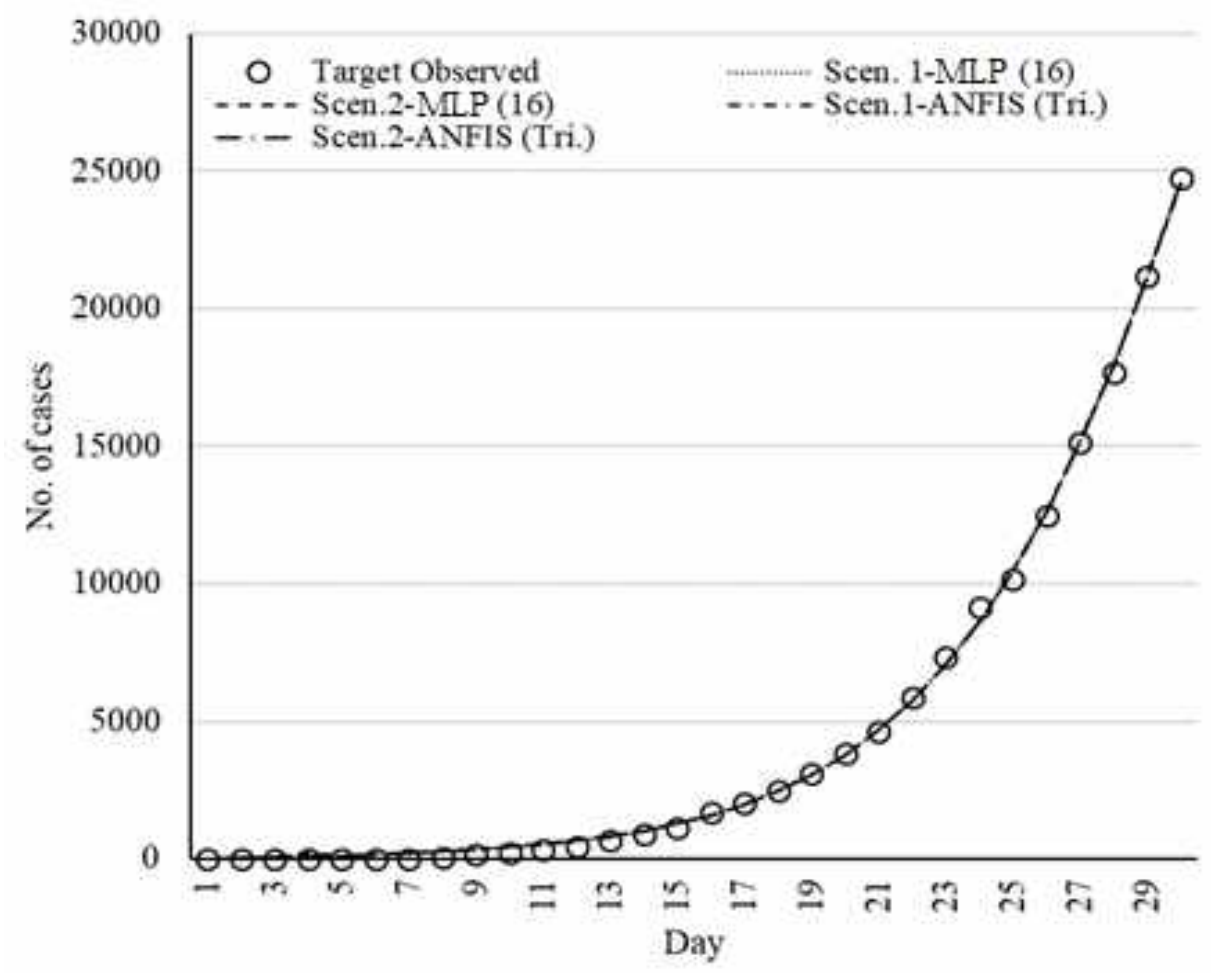

Figure 12. Set of models for Italy fitted by ML methods

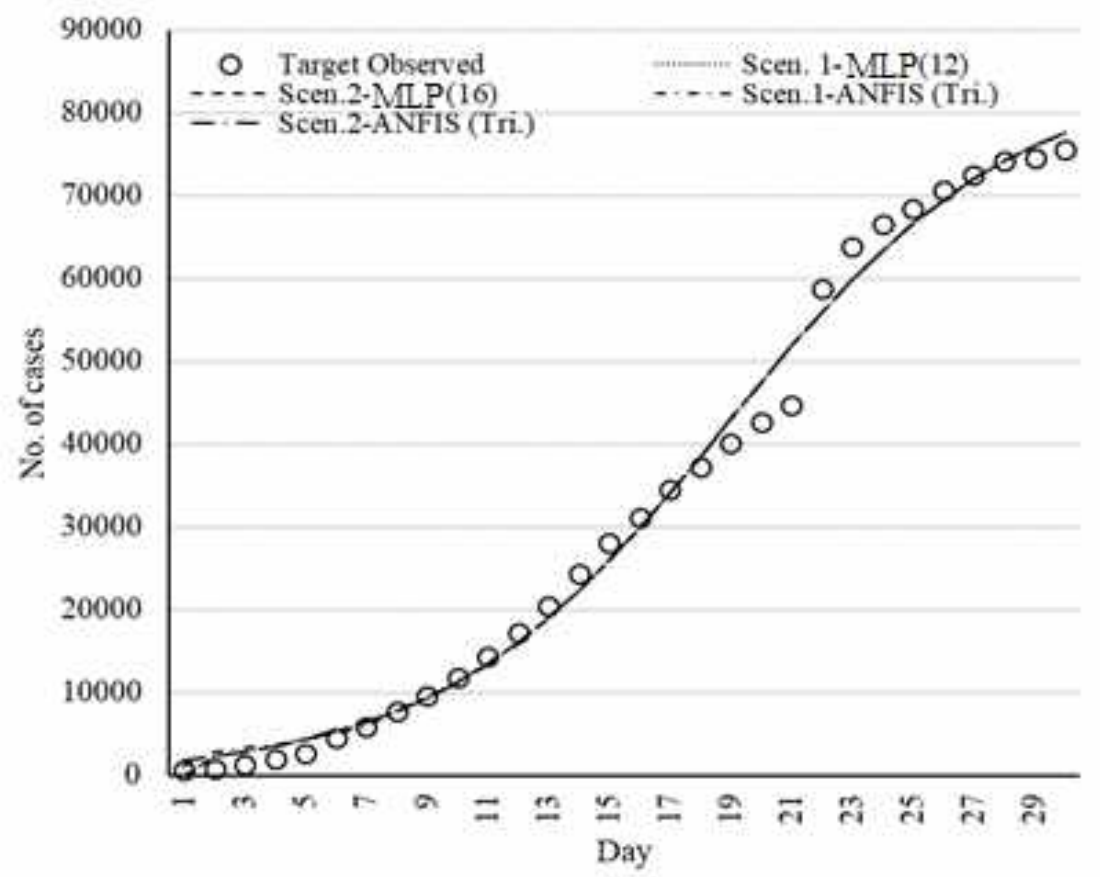

Figure 13. Set of models for China fitted by ML methods 


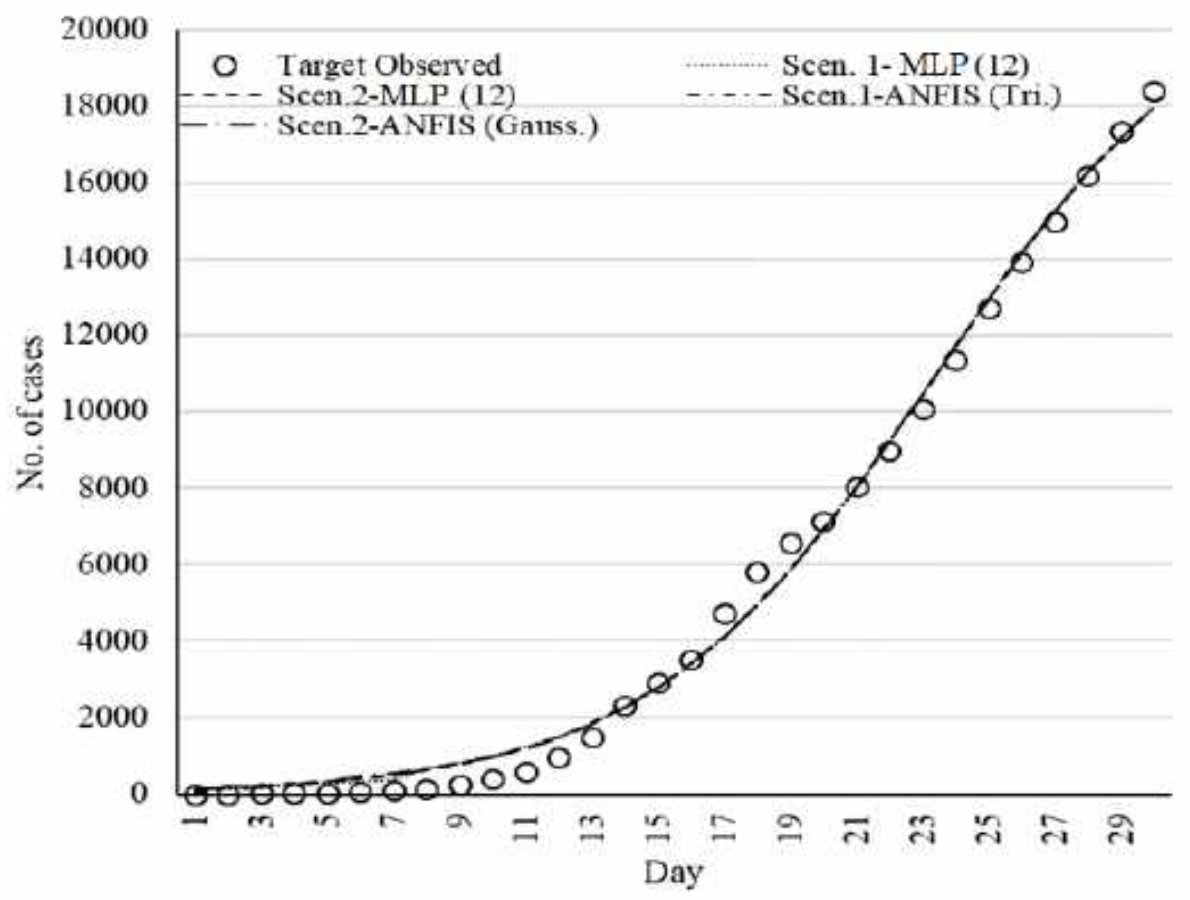

Figure 14. Set of models for Iran fitted by ML methods

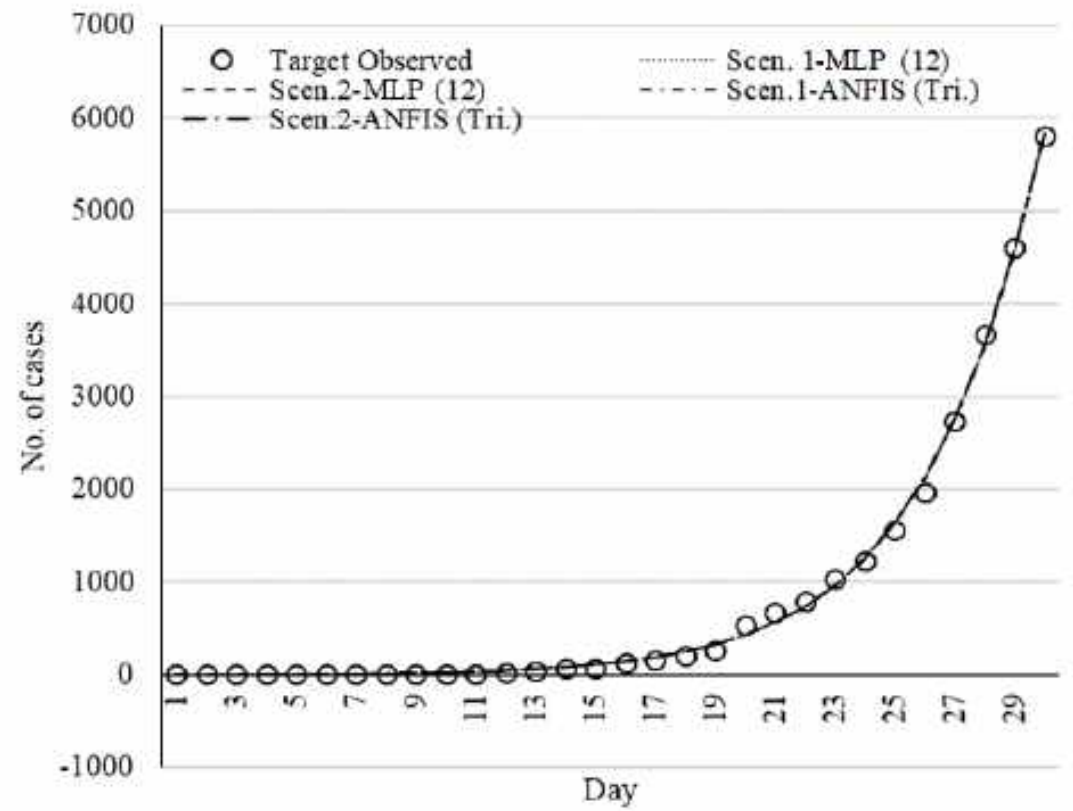

Figure 15. Set of models for Germany fitted by ML methods 


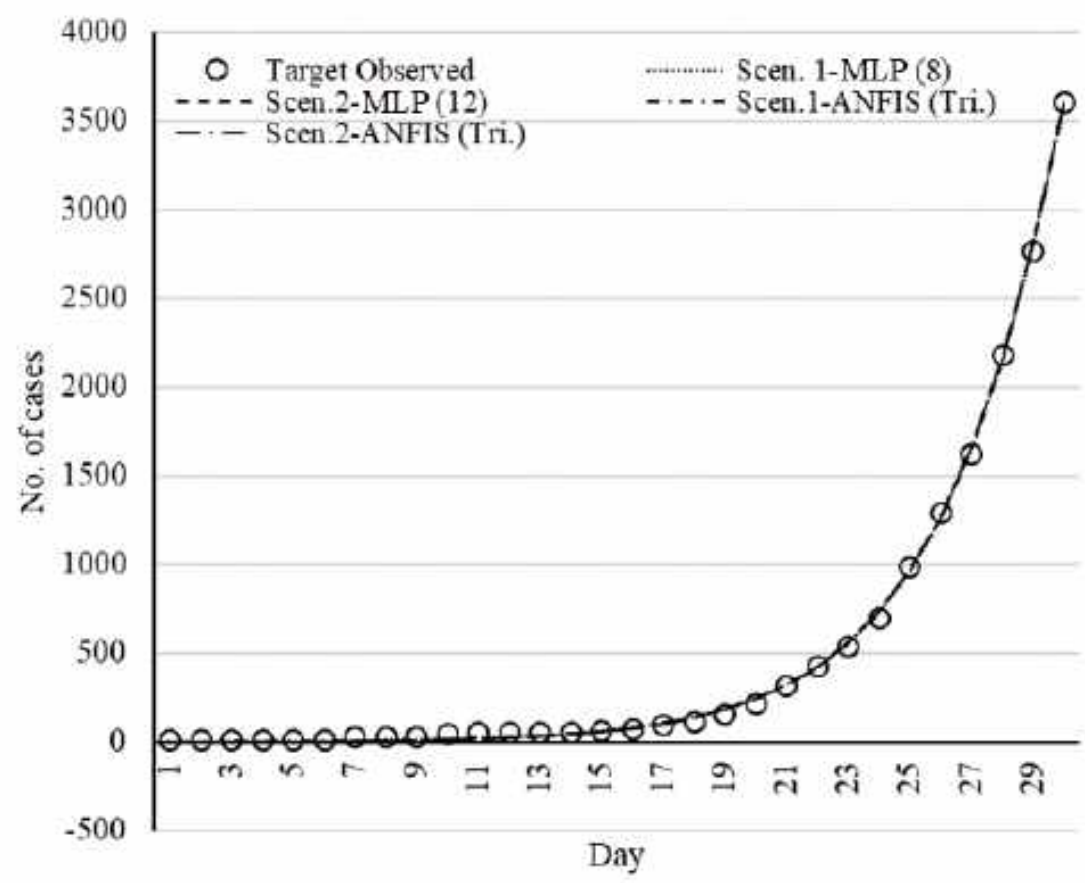

Figure 16. Set of models for USA fitted by ML methods

Comparing the fitted models

This section presents a comparison of the accuracy and performance of the selected models for the prediction of 30 days' outbreak. Figure 17 to 21 shows the deviation from the target values for the selected models.

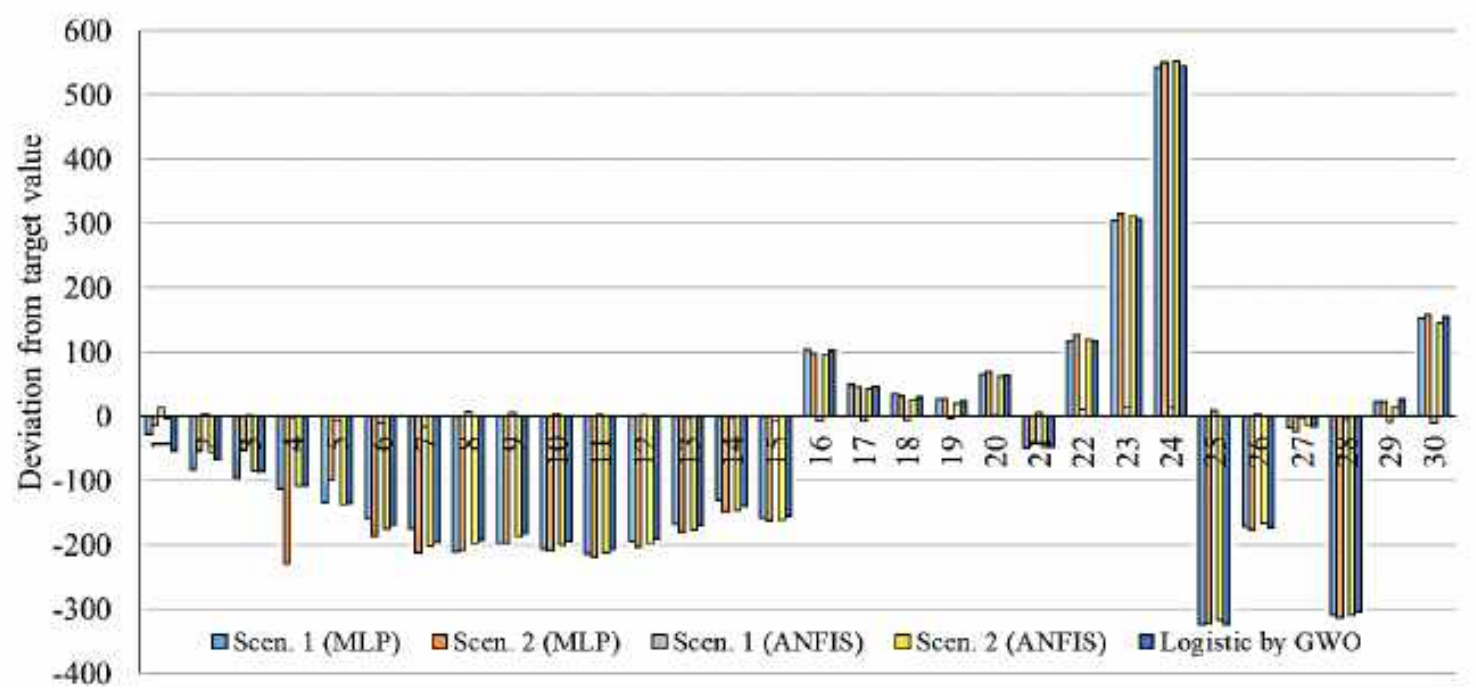

Figure 17. Deviation from target value for models related to Italy 


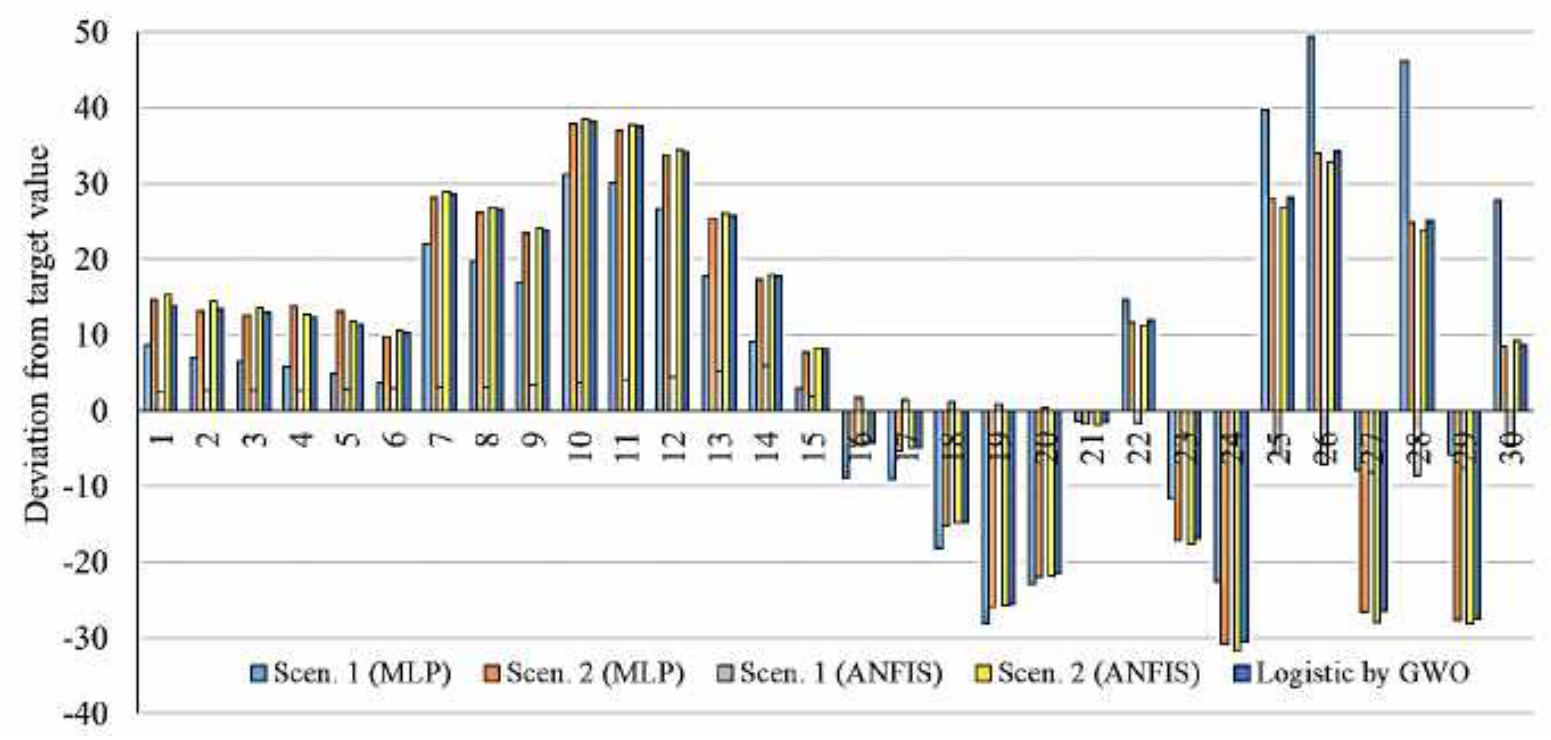

Figure 18. Deviation from target value for models related to China

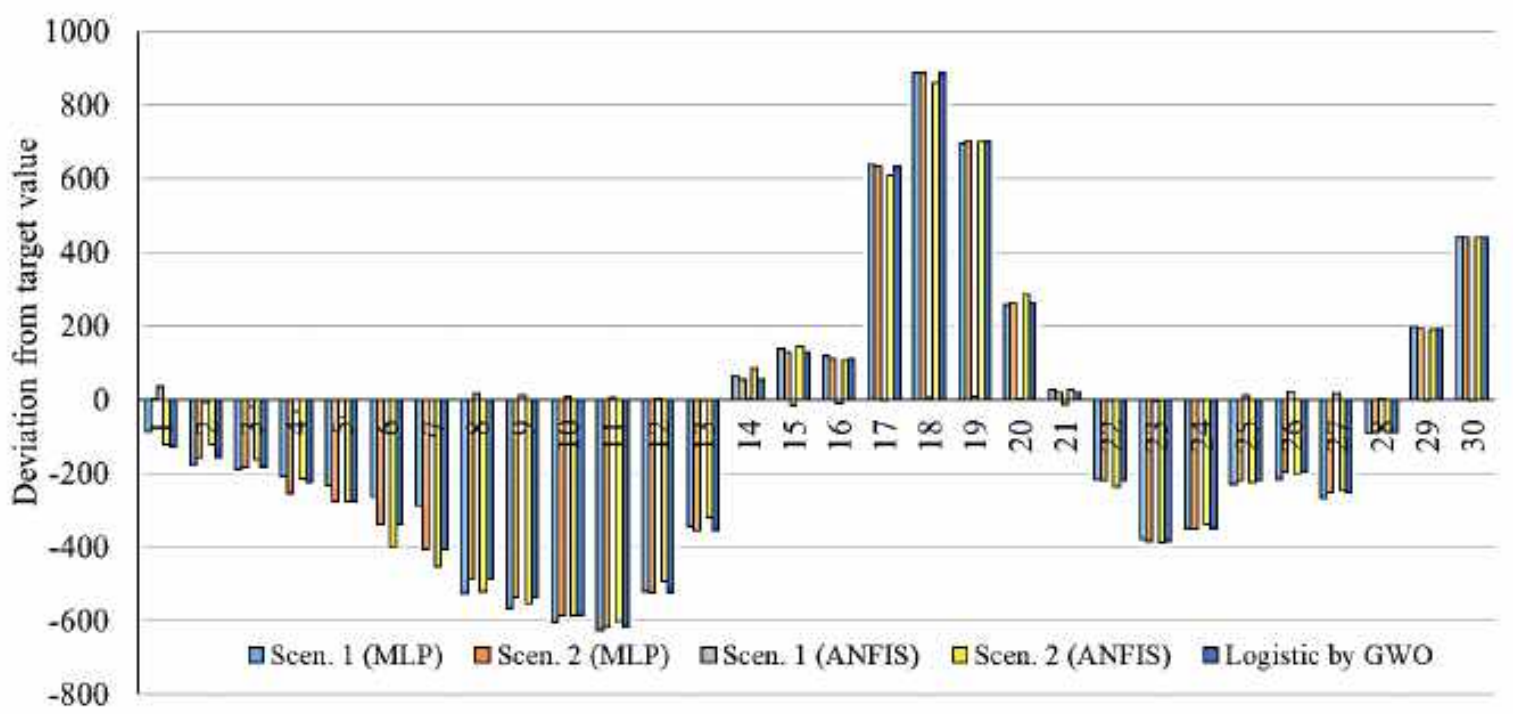

Figure 19. Deviation from target value for models related to Iran 


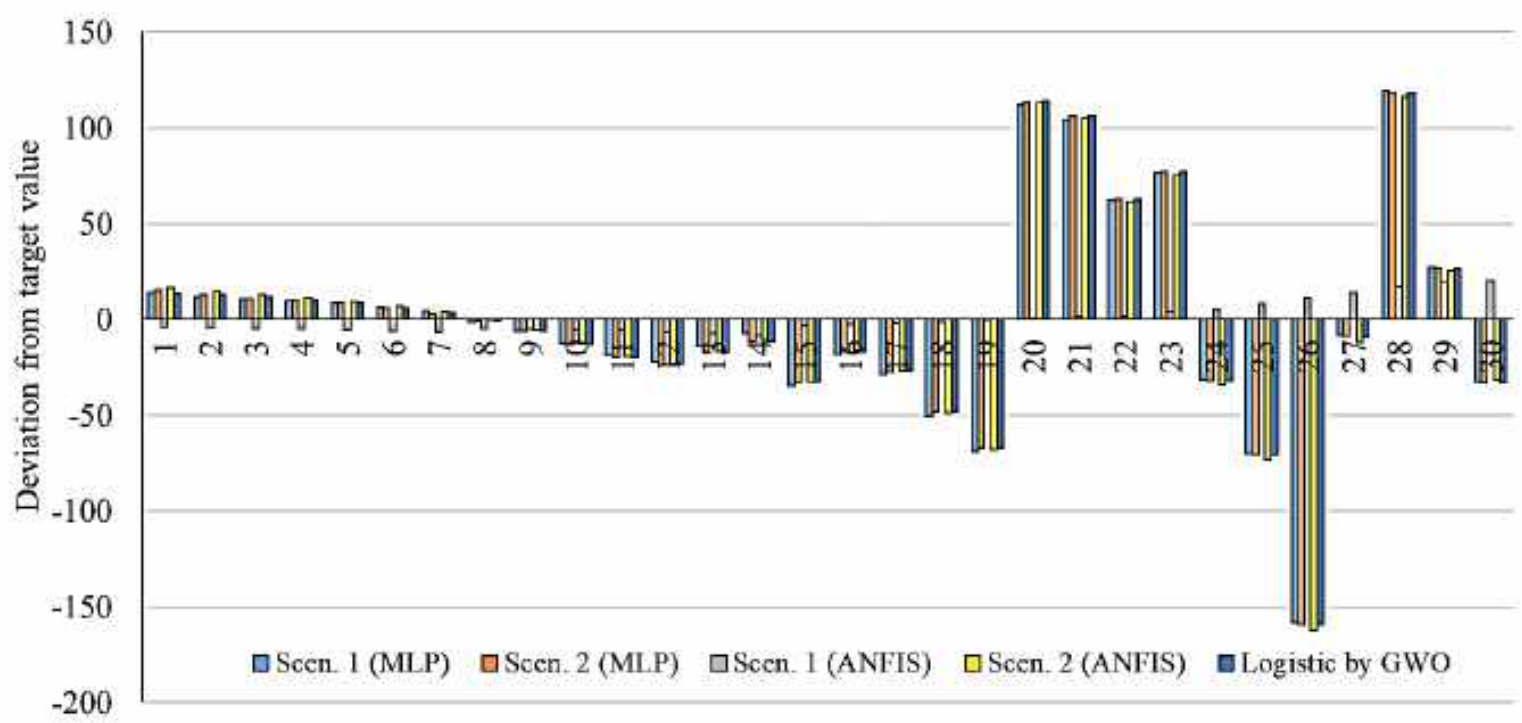

Figure 20. Deviation from target value for models related to Germany

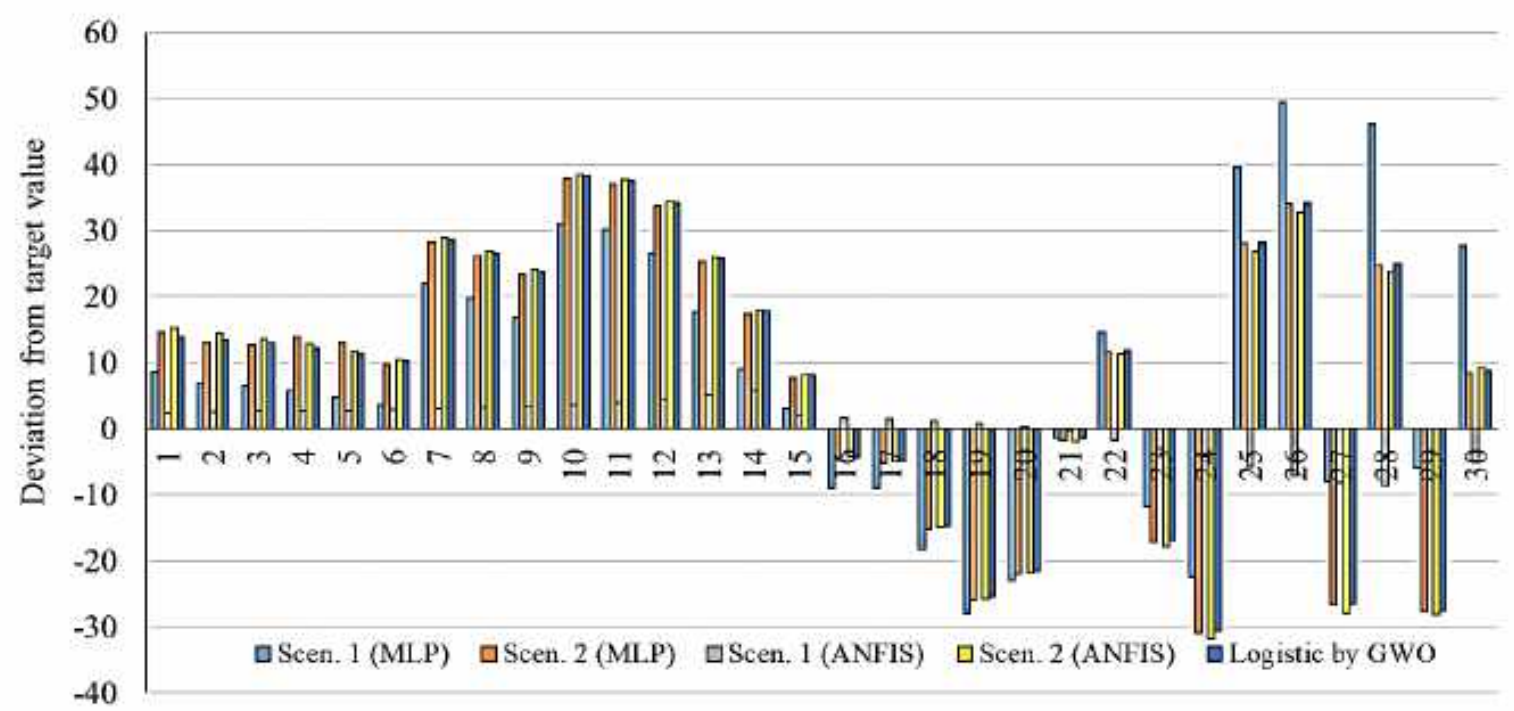

Figure 21. Deviation from target value for models related to USA

As is clear from Figure 17 to 21, the smallest deviation from the target values is related to the MLP for scenario 1 followed by MLP for scenario 2. This indicates the highest performance of the MLP method for the prediction of the outbreak.

Figures 22 to 26 present the outbreak prediction for 75 days and Tables 19 to 23 present the outbreak prediction for 150 days. 


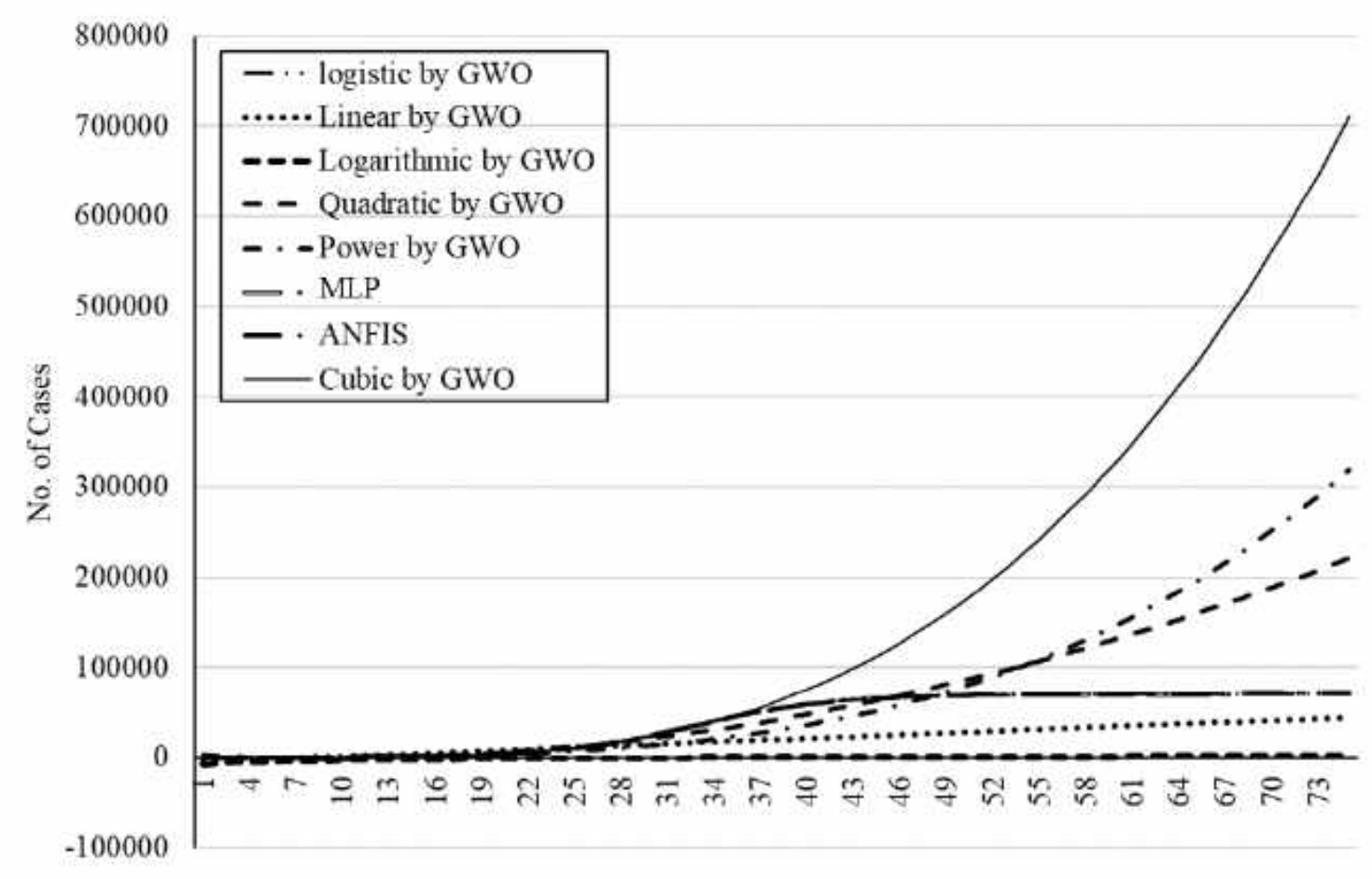

Figure 22. The outbreak prediction for Italy through 75 days

Table 19. The outbreak prediction for Italy through 150 days

\begin{tabular}{cccccccc}
\hline & $\begin{array}{c}\text { Logistic } \\
\text { by GWO }\end{array}$ & $\begin{array}{c}\text { Linear by } \\
\text { GWO }\end{array}$ & $\begin{array}{c}\text { Logarithmic } \\
\text { by GWO }\end{array}$ & $\begin{array}{c}\text { Quadratic } \\
\text { by GWO }\end{array}$ & $\begin{array}{c}\text { Power by } \\
\text { GWO }\end{array}$ & MLP & ANFIS \\
\hline $\begin{array}{c}\text { Day } \\
\text { 20th }\end{array}$ & 3794.045 & 7837.054 & -1280.93 & 5047.906 & 3225.523 & 3792.734 & 3796.738 \\
\hline $\begin{array}{c}\text { Day } \\
\text { 40th }\end{array}$ & 58966.55 & 21111.37 & 273.235 & 47914.4 & 35898.08 & 58966.74 & 58964.96 \\
\hline $\begin{array}{c}\text { Day } \\
\text { 60th }\end{array}$ & 70571.86 & 34385.68 & 1182.365 & 131597.7 & 146966.2 & 70571.66 & 70572.12 \\
\hline $\begin{array}{c}\text { Day } \\
80 \text { th }\end{array}$ & 70729.28 & 47659.99 & 1827.402 & 256097.8 & 399523.4 & 70729.27 & 70729.15 \\
\hline $\begin{array}{c}\text { Day } \\
\text { 100th }\end{array}$ & 70731.06 & 60934.31 & 2327.733 & 421414.7 & 867822 & 70731.09 & 70730.93 \\
\hline $\begin{array}{c}\text { Day } \\
\text { 120th }\end{array}$ & 70731.08 & 74208.62 & 2736.532 & 627548.4 & 1635643 & 70731.14 & 70730.87 \\
\hline $\begin{array}{c}\text { Day } \\
\text { 140th }\end{array}$ & 70731.08 & 87482.94 & 3082.167 & 874498.9 & 2795218 & 70731.19 & 70730.79 \\
\hline $\begin{array}{c}\text { Day } \\
\text { 150th }\end{array}$ & 70731.08 & 94120.09 & 3236.862 & 1013280 & 3552851 & 70731.21 & 70730.75 \\
\hline
\end{tabular}




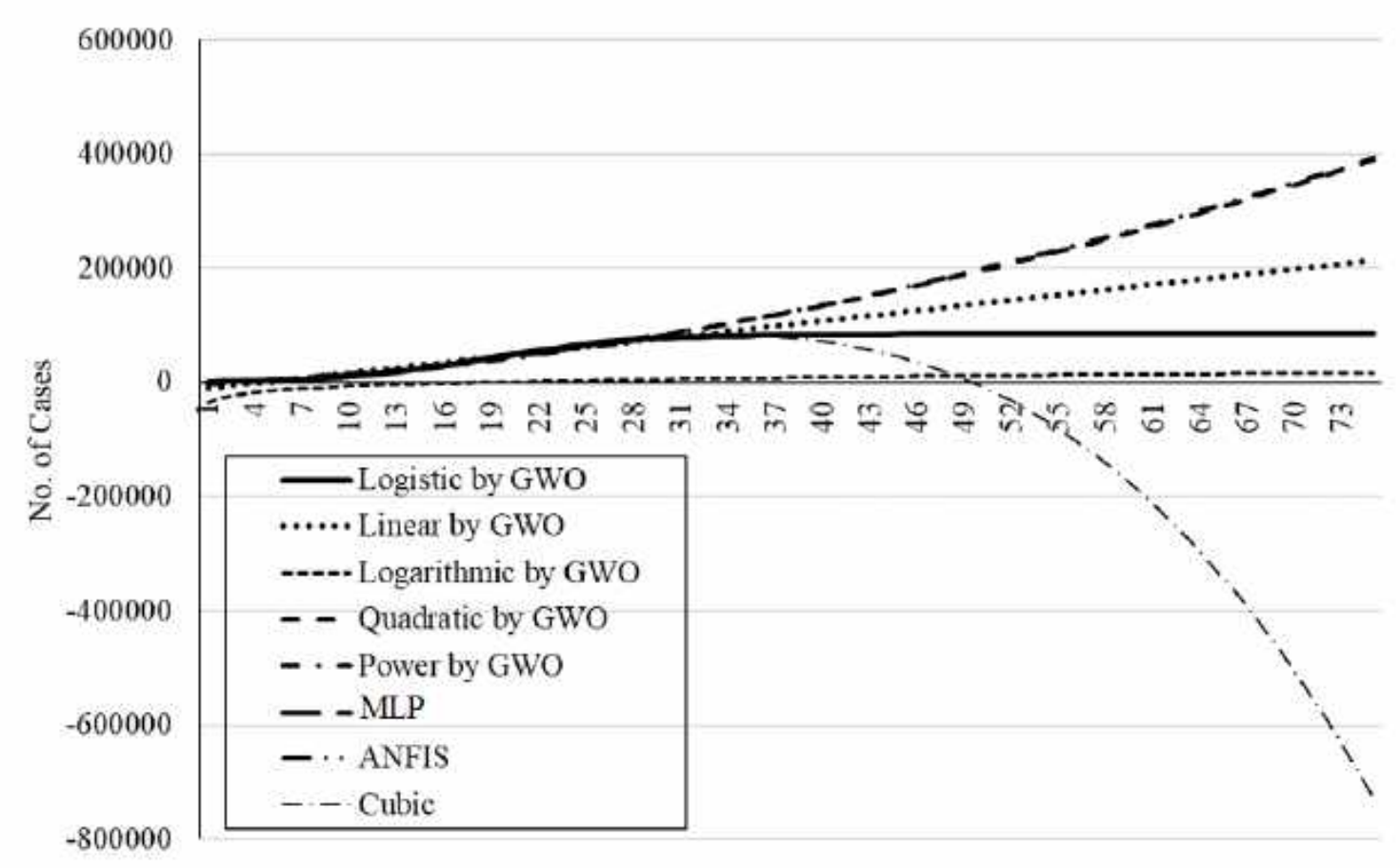

Figure 23. The outbreak prediction for China through 75 days

Table 20. The outbreak prediction for China through 150 days

\begin{tabular}{cccccccc}
\hline & $\begin{array}{c}\text { Logistic } \\
\text { by GWO }\end{array}$ & $\begin{array}{c}\text { Linear by } \\
\text { GWO }\end{array}$ & $\begin{array}{c}\text { Logarithmic } \\
\text { by GWO }\end{array}$ & $\begin{array}{c}\text { Quadratic } \\
\text { by GWO }\end{array}$ & $\begin{array}{c}\text { Power by } \\
\text { GWO }\end{array}$ & MLP & ANFIS \\
\hline $\begin{array}{c}\text { Day } \\
\text { 20th }\end{array}$ & 47397.6 & 47218.47 & 1341.899 & 44431.48 & 41916.55 & 47397.6 & 47360.98 \\
\hline $\begin{array}{c}\text { Day } \\
\text { 40th }\end{array}$ & 84030.16 & 107946.8 & 9507.249 & 134729.1 & 135599.1 & 84030.17 & 84030.39 \\
\hline $\begin{array}{c}\text { Day } \\
\text { 60th }\end{array}$ & 84996.7 & 168675.1 & 14283.67 & 265812 & 269471.3 & 84996.7 & 84996.67 \\
\hline $\begin{array}{c}\text { Day } \\
80 \text { th }\end{array}$ & 85011.08 & 229403.4 & 17672.6 & 437680.2 & 438660.2 & 85011.08 & 85011.05 \\
\hline $\begin{array}{c}\text { Day } \\
\text { 100th }\end{array}$ & 85011.29 & 290131.7 & 20301.26 & 650333.6 & 640132.8 & 85011.3 & 85011.22 \\
\hline $\begin{array}{c}\text { Day } \\
\text { 120th }\end{array}$ & 85011.3 & 350860 & 22449.02 & 903772.3 & 871733.6 & 85011.34 & 85011.13 \\
\hline $\begin{array}{c}\text { Day } \\
\text { 140th }\end{array}$ & 85011.3 & 411588.3 & 24264.94 & 1197996 & 1131815 & 85011.38 & 85011.05 \\
\hline $\begin{array}{c}\text { Day } \\
\text { 150th }\end{array}$ & 85011.3 & 441952.5 & 25077.68 & 1360403 & 1272113 & 85011.41 & 85011.01 \\
\hline
\end{tabular}




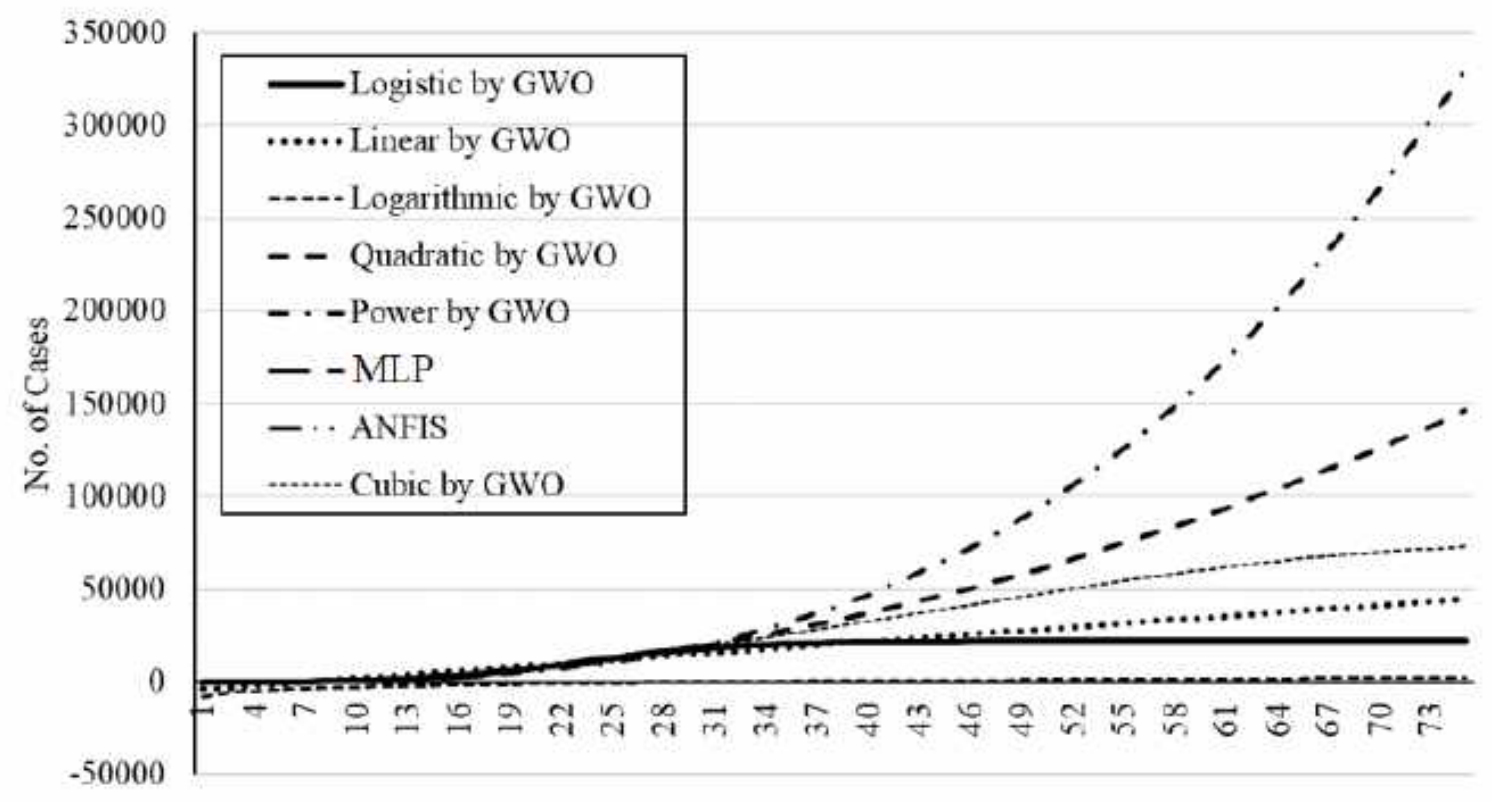

Figure 24. The outbreak prediction for Iran through 75 days

Table 21. The outbreak prediction for Iran through 150 days

\begin{tabular}{lccccccc}
\hline & Logistic by GWO & $\begin{array}{c}\text { Linear by } \\
\text { GWO }\end{array}$ & $\begin{array}{c}\text { Logarithmic } \\
\text { by GWO }\end{array}$ & $\begin{array}{c}\text { Quadratic } \\
\text { by GWO }\end{array}$ & $\begin{array}{c}\text { Power by } \\
\text { GWO }\end{array}$ & MLP & ANFIS \\
\hline Day 20th & 6898.344 & 8593.676 & -830.677 & 6993.955 & 5494.377 & 6902.315 & 6875.585 \\
\hline Day 40th & 21455.58 & 21715.05 & 809.8719 & 37087.98 & 47060.48 & 21457.4 & 21456.65 \\
\hline Day 60th & 21931.01 & 34836.43 & 1769.531 & 90592.56 & 165300.1 & 21932.24 & 21930.68 \\
\hline Day 80th & 21936 & 47957.8 & 2450.42 & 167507.7 & 403082.8 & 21935.1 & 21935.54 \\
\hline Day 100th & 21936.05 & 61079.18 & 2978.559 & 267833.4 & 804764.4 & 21935.11 & 21935.6 \\
\hline Day 120th & 21936.05 & 74200.55 & 3410.08 & 391569.6 & 1415829 & 21935.12 & 21935.63 \\
\hline Day 140th & 21936.05 & 87321.93 & 3774.925 & 538716.4 & 2282679 & 21935.13 & 21935.65 \\
\hline Day 150th & 21936.05 & 93882.61 & 3938.219 & 621068.7 & 2826737 & 21935.13 & 21935.67 \\
\hline
\end{tabular}




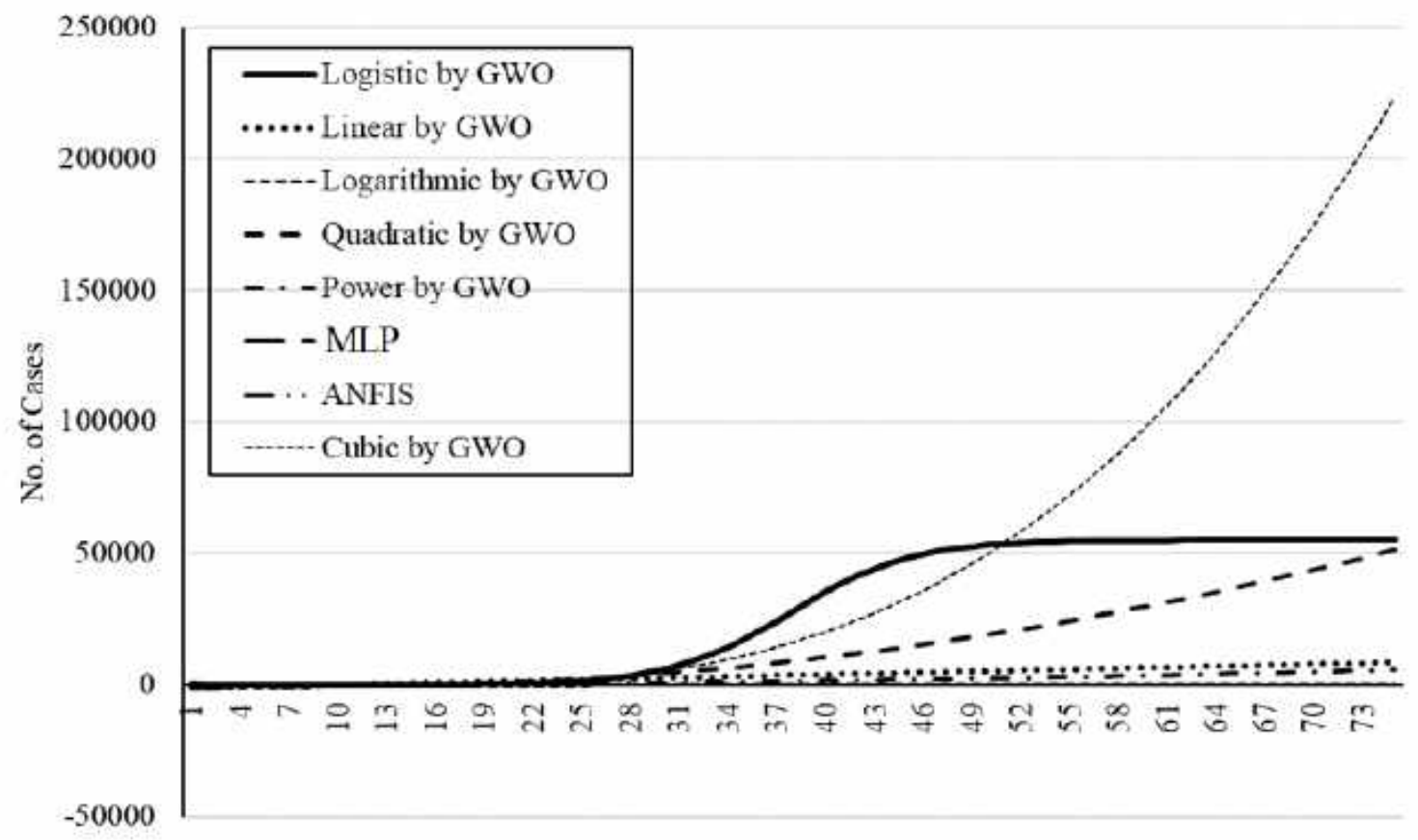

Figure 25. The outbreak prediction for Germany through 75 days

Table 22. The outbreak prediction for Germany through 150 days

\begin{tabular}{cccccccc}
\hline & $\begin{array}{c}\text { Logistic by } \\
\text { GWO }\end{array}$ & $\begin{array}{c}\text { Linear by } \\
\text { GWO }\end{array}$ & $\begin{array}{c}\text { Logarithmic by } \\
\text { GWO }\end{array}$ & $\begin{array}{c}\text { Quadratic by } \\
\text { GWO }\end{array}$ & $\begin{array}{c}\text { Power by } \\
\text { GWO }\end{array}$ & MLP & ANFIS \\
\hline $\begin{array}{c}\text { Day } \\
\text { 20th }\end{array}$ & 431.027 & 1438.128 & -279.772 & 763.1467 & 400.0548 & 432.8991 & 431.8119 \\
\hline $\begin{array}{c}\text { Day } \\
\text { 40th }\end{array}$ & 35356.27 & 4006.551 & 9.199328 & 10492.96 & 1624.405 & 35355.14 & 35355.72 \\
\hline $\begin{array}{c}\text { Day } \\
\text { 60th }\end{array}$ & 55043.44 & 6574.974 & 178.2366 & 30100.56 & 3687.126 & 55036.14 & 55044.03 \\
\hline $\begin{array}{c}\text { Day } \\
80 \text { th }\end{array}$ & 55179.07 & 9143.397 & 298.1705 & 59585.93 & 6595.829 & 55179.05 & 55178.88 \\
\hline $\begin{array}{c}\text { Day } \\
100 \text { th }\end{array}$ & 55179.67 & 11711.82 & 391.1984 & 98949.09 & 10355.87 & 55179.9 & 55179.47 \\
\hline $\begin{array}{c}\text { Day } \\
\text { 120th }\end{array}$ & 55179.67 & 14280.24 & 467.2078 & 148190 & 14971.42 & 55179.92 & 55179.42 \\
\hline $\begin{array}{c}\text { Day } \\
\text { 140th }\end{array}$ & 55179.67 & 16848.66 & 531.4728 & 207308.7 & 20445.86 & 55179.94 & 55179.37 \\
\hline $\begin{array}{c}\text { Day } \\
\text { 150th }\end{array}$ & 55179.67 & 18132.88 & 560.2357 & 240572.3 & 23506.09 & 55179.96 & 55179.35 \\
\hline
\end{tabular}




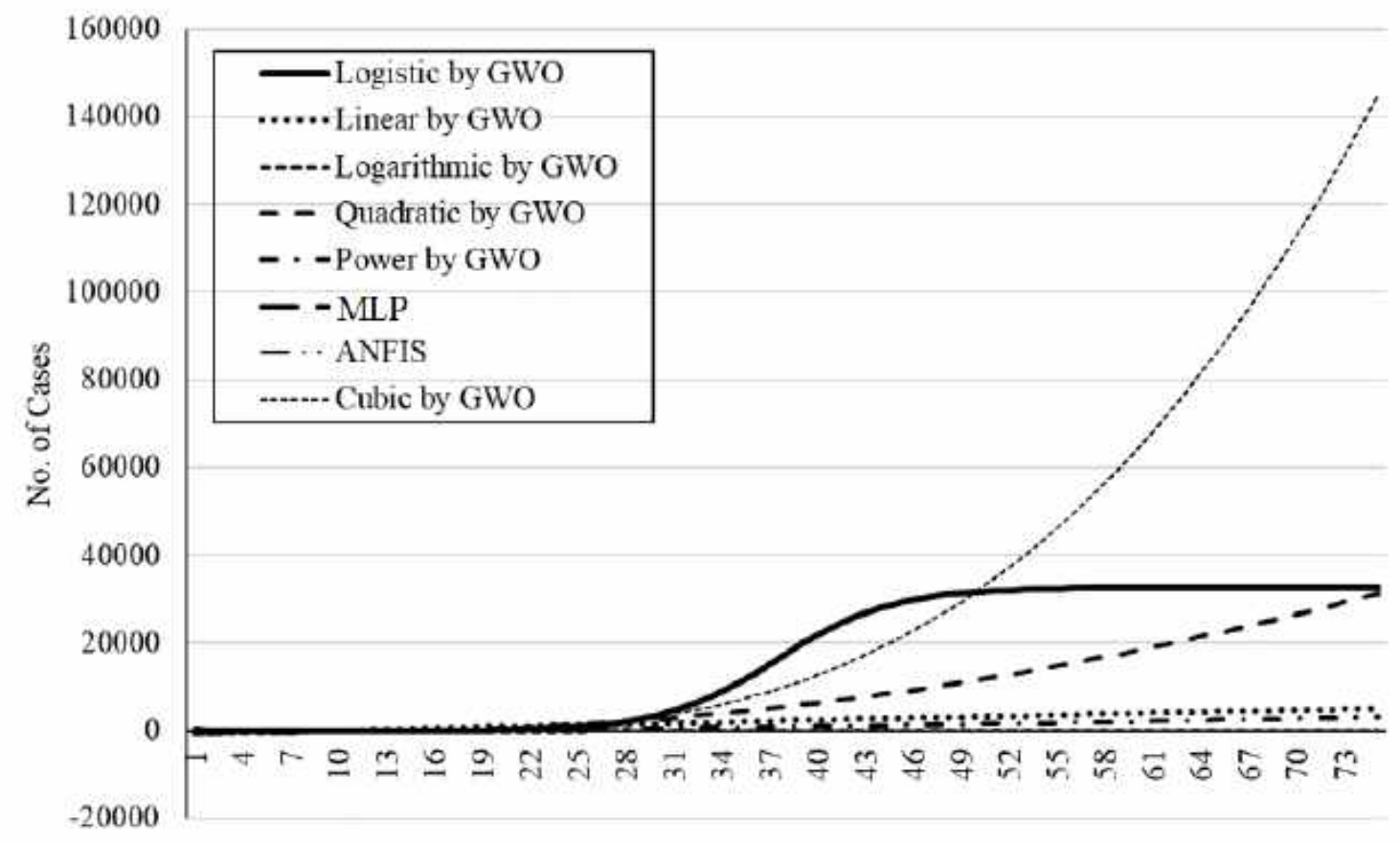

Figure 26. The outbreak prediction for the USA through 75 days

Table 23. The outbreak prediction for the USA for 150 days

\begin{tabular}{cccccccc}
\hline & $\begin{array}{c}\text { Logistic by } \\
\text { GWO }\end{array}$ & $\begin{array}{c}\text { Linear by } \\
\text { GWO }\end{array}$ & $\begin{array}{c}\text { Logarithmic by } \\
\text { GWO }\end{array}$ & $\begin{array}{c}\text { Quadratic by } \\
\text { GWO }\end{array}$ & $\begin{array}{c}\text { Power by } \\
\text { GWO }\end{array}$ & MLP & ANFIS \\
\hline $\begin{array}{c}\text { Day } \\
\text { 20th }\end{array}$ & 242.6091 & 869.8855 & -156.73 & 456.0663 & 309.616 & 244.0038 & 243.6504 \\
\hline $\begin{array}{c}\text { Day } \\
40 \text { th }\end{array}$ & 21951.15 & 2406.562 & 15.85698 & 6383.264 & 1031.324 & 21942.25 & 21948.25 \\
\hline $\begin{array}{c}\text { Day } \\
60 \text { th }\end{array}$ & 32547.08 & 3943.238 & 116.8138 & 18366.35 & 2084.876 & 32552.6 & 32548.47 \\
\hline $\begin{array}{c}\text { Day } \\
80 \text { th }\end{array}$ & 32604.34 & 5479.914 & 188.4437 & 36405.33 & 3435.319 & 32606.19 & 32604.47 \\
\hline $\begin{array}{c}\text { Day } \\
100 \text { th }\end{array}$ & 32604.55 & 7016.591 & 244.0043 & 60500.21 & 5060.548 & 32606.63 & 32604.72 \\
\hline $\begin{array}{c}\text { Day } \\
120 \text { th }\end{array}$ & 32604.55 & 8553.267 & 289.4005 & 90650.97 & 6944.676 & 32606.7 & 32604.76 \\
\hline $\begin{array}{c}\text { Day } \\
140 \text { th }\end{array}$ & 32604.55 & 10089.94 & 327.7825 & 126857.6 & 9075.446 & 32606.78 & 32604.8 \\
\hline $\begin{array}{c}\text { Day } \\
\text { 150th }\end{array}$ & 32604.55 & 10858.28 & 344.9611 & 147231.9 & 10230.16 & 32606.81 & 32604.82 \\
\hline
\end{tabular}

\section{Discussion}

The parameters of several simple mathematical models (i.e., logistic, linear, logarithmic, quadratic, cubic, compound, power and exponential) were fitted using GA, PSO, and GWO. The logistic model outperformed other methods and showed promising results on training for 30 days. Extrapolation of the prediction beyond the original observation range of 30-days should not be 
expected to be realistic considering the new statistics. The fitted models generally showed low accuracy and also weak generalization ability for the five countries. Although the prediction for China was promising, the model was insufficient for extrapolation, as expected. In turn, the logistic GWO outperformed the PSO and GA and the computational cost for GWO was reported as satisfactory. Consequently, for further assessment of the ML models, the logistic model fitted with GWO was used for comparative analysis.

In the next step, for introducing the machine learning methods for time-series prediction, two scenarios were proposed. Scenario 1 considered four data samples from the progress of the infection from previous days, as reported in table 3. The sampling for data processing was done weekly for scenario 1 . However, scenario 2 was devoted to daily sampling for all previous consecutive days. Providing these two scenarios expanded the scope of this study. Training and test results for the two machine learning models (MLP and ANFIS) were considered for the two scenarios. A detailed investigation was also carried out to explore the most suitable number of neurons. For the MLP, the performances of using 8,12 and 16 neurons were analyzed throughout the study. For the ANFIS, the membership function (MF) types of Tri, Trap, and Gauss were analyzed throughout the study. The five counties of Italy, China, Iran, Germany, and USA were considered. The performance of both ML models for these countries varied amongst the two different scenarios. Given the observed results, it is not possible to select the most suitable scenario. Therefore, both daily and weekly sampling can be used in machine learning modeling. Comparison between analytical and machine learning models using the deviation from the target value (figures 17 to 21) indicated that the MLP in both scenarios delivered the most accurate results. Extrapolation for long-term prediction of up to 150 days using the ML models was tested. The actual prediction of MLP and ANFIS for the five countries was reported which showed the progression of the outbreak.

This paper evaluated the applicability of two machine learning models, MLP and ANFIS, for predicting the COVID-19 outbreak. The models showed promising results in terms of predicting the time series without the assumptions that epidemiological models require. Machine learning models, as an alternative to epidemiological models, showed potential in predicting COVID-19, as they did for modeling other outbreaks (see table 1). Considering the availability of only a small amount of training data, it is expected that machine learning will be developed further as the basis for, or a component of, future outbreak prediction models.

Here, it is worth mentioning that machine learning can also be found useful in dealing with the challenges that SEIR models face for COVID-19. For example, the number of cases reported by worldometer is not the number of infecteds ( $E$ in the SEIR model). For example, the number of cases reported by worldometer for the UK situation, is the number of people tested. Also, data for the number of infectious people ( $I$ in SEIR) is a challenging matter, as many people who might be infectious may not turn up for testing, for example, if their symptoms are mild. Although we have better data on the number of people who are admitted to hospital and the number who die, these are not $R$ either since it is generally accepted that most people with COVID-19 recover without entering hospital. Considering this data problem, it is extremely difficult to fit SEIR models satisfactorily. Considering such challenges, for future research, the ability of machine learning for estimation of the missing information on the number of exposed $E$ or infecteds can be evaluated. Furthermore, the temporal non-stationarity data in control measures can be also investigated using machine learning.

\section{Conclusions}

The global pandemic of the severe acute respiratory syndrome Coronavirus 2 (SARS-CoV-2) has become the primary national security issue of many nations. Advancement of accurate prediction models for the outbreak is essential to provide insights into the spread and consequences of this infectious disease. Due to the high level of uncertainty and lack of crucial data, standard epidemiological models have shown low accuracy for long-term prediction. This paper presents a comparative analysis of ML and soft computing models to predict the COVID-19 outbreak. The results of two ML models (MLP and ANFIS) reported a high generalization ability for long-term prediction. With respect to the results reported in this paper and due to the highly complex nature of 
the COVID-19 outbreak and differences from nation-to-nation, this study suggests ML as an effective tool to model the time series of outbreak. We should note that this paper provides an initial benchmarking to demonstrate the potential of machine learning for future research.

For the advancement of higher performance models for long-term prediction, future research should be devoted to comparative studies on various ML models for individual countries. Due to the fundamental differences between the outbreak in various countries, advancement of global models with generalization ability would not be feasible. As observed and reported in many studies, it is unlikely that an individual outbreak will be replicated elsewhere [1].

Although the most difficult prediction is to estimate the maximum number of infected patients, estimation of the individual mortality rate ( $n$ (deaths) / $n$ (infecteds)) is also essential. The mortality rate is particularly important to estimate accurately the number of patients and the required beds in intensive care units. For future research, modeling the mortality rate would be of the utmost importance for nations to plan for new facilities. For future research integration of machine learning and SIR/SEIR models is suggested to enhance the existing standard epidemiological models in terms of accuracy and longer lead time.

\section{Nomenclatures}

\begin{tabular}{|l|l|l|l|}
\hline Multi-layered perceptron & MLP & Grey wolf optimization & GWO \\
\hline Adaptive network-based fuzzy inference system & ANFIS & Mean square error & MSE \\
\hline Susceptible-infected-recovered & SIR & Root mean square error & RMSE \\
\hline Call data record & CDR & Artificial intelligence & AI \\
\hline Classification and regression tree & CART & Artificial neural network & ANN \\
\hline Evolutionary algorithms & EA & Triangular & Tri. \\
\hline Genetic algorithm & GA & Gaussian & Gauss. \\
\hline Particle swarm optimization & PSO & Trapezoidal & Trap. \\
\hline Membership function & MF & Machine learning & ML \\
\hline
\end{tabular}

Author Contributions: Conceptualization, X.X. and Y.Y.; methodology, X.X.; software, X.X.; validation, X.X., Y.Y. and Z.Z.; formal analysis, X.X.; investigation, X.X.; resources, X.X.; data curation, X.X.; writing-original draft preparation, X.X.; writing-review and editing, X.X.; visualization, X.X.; supervision, X.X.; project administration, X.X.; funding acquisition, Y.Y. All authors have read and agreed to the published version of the manuscript.

Funding: This research is supported within the project of "Support of research and development activities of the J. Selye University in the field of Digital Slovakia and creative industry" of the Research and Innovation Operational Programme (ITMS code: NFP313010T504) co-funded by the European Regional Development Fund.

Acknowledgments: We acknowledge the financial support of this work by the Hungarian State and the European Union under the EFOP-3.6.1-16-2016-00010 project and the 2017-1.3.1-VKE-2017-00025 project.

Conflicts of Interest: The authors declare no conflict of interest.

\section{References}

1. Remuzzi, A.; Remuzzi, G. COVID-19 and Italy: what next? Lancet 2020. 
2. Ivanov, D. Predicting the impacts of epidemic outbreaks on global supply chains: A simulation-based analysis on the coronavirus outbreak (COVID-19/SARS-CoV-2) case. Transp. Res. Part E Logist. Transp. Rev. 2020, 136, doi:10.1016/j.tre.2020.101922.

3. Koolhof, I.S.; Gibney, K.B.; Bettiol, S.; Charleston, M.; Wiethoelter, A.; Arnold, A.L.; Campbell, P.T.; Neville, P.J.; Aung, P.; Shiga, T., et al. The forecasting of dynamical Ross River virus outbreaks: Victoria, Australia. Epidemics 2020, 30, doi:10.1016/j.epidem.2019.100377.

4. Darwish, A.; Rahhal, Y.; Jafar, A. A comparative study on predicting influenza outbreaks using different feature spaces: application of influenza-like illness data from Early Warning Alert and Response System in Syria. BMC Res. Notes 2020, 13, 33, doi:10.1186/s13104-020-4889-5.

5. Rypdal, M.; Sugihara, G. Inter-outbreak stability reflects the size of the susceptible pool and forecasts magnitudes of seasonal epidemics. Nat. Commun. 2019, 10, doi:10.1038/s41467-019-10099-y.

6. Scarpino, S.V.; Petri, G. On the predictability of infectious disease outbreaks. Nat. Commun. 2019, 10, doi:10.1038/s41467-019-08616-0.

7. Zhan, Z.; Dong, W.; Lu, Y.; Yang, P.; Wang, Q.; Jia, P. Real-Time Forecasting of Hand-Foot-and-Mouth Disease Outbreaks using the Integrating Compartment Model and Assimilation Filtering. Sci. Rep. 2019, 9, doi:10.1038/s41598-019-38930-y.

8. Koike, F.; Morimoto, N. Supervised forecasting of the range expansion of novel non-indigenous organisms: Alien pest organisms and the $2009 \mathrm{H1N1}$ flu pandemic. Global Ecol. Biogeogr. 2018, 27, 991 1000, doi:10.1111/geb.12754.

9. Dallas, T.A.; Carlson, C.J.; Poisot, T. Testing predictability of disease outbreaks with a simple model of pathogen biogeography. R. Soc. Open Sci. 2019, 6, doi:10.1098/rsos.190883.

10. de Groot, M.; Ogris, N. Short-term forecasting of bark beetle outbreaks on two economically important conifer tree species. For. Ecol. Manage. 2019, 450, doi:10.1016/j.foreco.2019.117495.

11. Kelly, J.D.; Park, J.; Harrigan, R.J.; Hoff, N.A.; Lee, S.D.; Wannier, R.; Selo, B.; Mossoko, M.; Njoloko, B.; Okitolonda-Wemakoy, E., et al. Real-time predictions of the 2018-2019 Ebola virus disease outbreak in the Democratic Republic of the Congo using Hawkes point process models. Epidemics 2019, 28, doi:10.1016/j.epidem.2019.100354.

12. Maier, B.F.; Brockmann, D. Effective containment explains sub-exponential growth in confirmed cases of recent COVID-19 outbreak in Mainland China. medRxiv 2020, 10.1101/2020.02.18.20024414, 2020.2002.2018.20024414, doi:10.1101/2020.02.18.20024414.

13. Pan, J.R.; Huang, Z.Q.; Chen, K. [Evaluation of the effect of varicella outbreak control measures through a discrete time delay SEIR model]. Zhonghua Yu Fang Yi Xue Za Zhi 2012, 46, 343-347.

14. Zha, W.T.; Pang, F.R.; Zhou, N.; Wu, B.; Liu, Y.; Du, Y.B.; Hong, X.Q.; Lv, Y. Research about the optimal strategies for prevention and control of varicella outbreak in a school in a central city of China: Based on an SEIR dynamic model. Epidemiol. Infect. 2020, 10.1017/S0950268819002188, doi:10.1017/S0950268819002188.

15. Dantas, E.; Tosin, M.; Cunha, A., Jr. Calibration of a SEIR-SEI epidemic model to describe the Zika virus outbreak in Brazil. Appl. Math. Comput. 2018, 338, 249-259, doi:10.1016/j.amc.2018.06.024.

16. Leonenko, V.N.; Ivanov, S.V. Fitting the SEIR model of seasonal influenza outbreak to the incidence data for Russian cities. Russ J Numer Anal Math Modell 2016, 31, 267-279, doi:10.1515/rnam-2016-0026.

17. Imran, M.; Usman, M.; Dur-e-Ahmad, M.; Khan, A. Transmission Dynamics of Zika Fever: A SEIR Based Model. Differ. Equ. Dyn. Syst. 2020, 10.1007/s12591-017-0374-6, doi:10.1007/s12591-017-0374-6. 
18. Miranda, G.H.B.; Baetens, J.M.; Bossuyt, N.; Bruno, O.M.; De Baets, B. Real-time prediction of influenza outbreaks in Belgium. Epidemics 2019, 28, doi:10.1016/j.epidem.2019.04.001.

19. Sinclair, D.R.; Grefenstette, J.J.; Krauland, M.G.; Galloway, D.D.; Frankeny, R.J.; Travis, C.; Burke, D.S.; Roberts, M.S. Forecasted Size of Measles Outbreaks Associated With Vaccination Exemptions for Schoolchildren. JAMA Netw Open 2019, 2, e199768, doi:10.1001/jamanetworkopen.2019.9768.

20. Zhao, S.; Musa, S.S.; Fu, H.; He, D.; Qin, J. Simple framework for real-time forecast in a data-limited situation: The Zika virus (ZIKV) outbreaks in Brazil from 2015 to 2016 as an example. Parasites Vectors 2019, 12, doi:10.1186/s13071-019-3602-9.

21. Fast, S.M.; Kim, L.; Cohn, E.L.; Mekaru, S.R.; Brownstein, J.S.; Markuzon, N. Predicting social response to infectious disease outbreaks from internet-based news streams. Ann. Oper. Res. 2018, 263, 551-564, doi:10.1007/s10479-017-2480-9.

22. McCabe, C.M.; Nunn, C.L. Effective network size predicted from simulations of pathogen outbreaks through social networks provides a novel measure of structure-standardized group size. Front. Vet. Sci. 2018, 5, doi:10.3389/fvets.2018.00071.

23. Bragazzi, N.L.; Mahroum, N. Google trends predicts present and future plague cases during the plague outbreak in Madagascar: Infodemiological study. J. Med. Internet Res. 2019, 21, doi:10.2196/13142.

24. Jain, R.; Sontisirikit, S.; Iamsirithaworn, S.; Prendinger, H. Prediction of dengue outbreaks based on disease surveillance, meteorological and socio-economic data. BMC Infect. Dis. 2019, 19, doi:10.1186/s12879-019-3874-x.

25. Kim, T.H.; Hong, K.J.; Shin, S.D.; Park, G.J.; Kim, S.; Hong, N. Forecasting respiratory infectious outbreaks using ED-based syndromic surveillance for febrile ED visits in a Metropolitan City. Am. J. Emerg. Med. 2019, 37, 183-188, doi:10.1016/j.ajem.2018.05.007.

26. Zhong, L.; Mu, L.; Li, J.; Wang, J.; Yin, Z.; Liu, D. Early Prediction of the 2019 Novel Coronavirus Outbreak in the Mainland China Based on Simple Mathematical Model. IEEE Access 2020, 8, 5176151769, doi:10.1109/ACCESS.2020.2979599.

27. Wu, J.T.; Leung, K.; Leung, G.M. Nowcasting and forecasting the potential domestic and international spread of the 2019-nCoV outbreak originating in Wuhan, China: a modelling study. Lancet 2020, 395, 689-697, doi:10.1016/S0140-6736(20)30260-9.

28. Reis, J.; Yamana, T.; Kandula, S.; Shaman, J. Superensemble forecast of respiratory syncytial virus outbreaks at national, regional, and state levels in the United States. Epidemics 2019, 26, 1-8, doi:10.1016/j.epidem.2018.07.001.

29. Burke, R.M.; Shah, M.P.; Wikswo, M.E.; Barclay, L.; Kambhampati, A.; Marsh, Z.; Cannon, J.L.; Parashar, U.D.; Vinjé, J.; Hall, A.J. The Norovirus Epidemiologic Triad: Predictors of Severe Outcomes in US Norovirus Outbreaks, 2009-2016. J. Infect. Dis. 2019, 219, 1364-1372, doi:10.1093/infdis/jiy569.

30. Carlson, C.J.; Dougherty, E.; Boots, M.; Getz, W.; Ryan, S.J. Consensus and conflict among ecological forecasts of Zika virus outbreaks in the United States. Sci. Rep. 2018, 8, doi:10.1038/s41598-018-22989-0.

31. Kleiven, E.F.; Henden, J.A.; Ims, R.A.; Yoccoz, N.G. Seasonal difference in temporal transferability of an ecological model: near-term predictions of lemming outbreak abundances. Sci. Rep. 2018, 8, doi:10.1038/s41598-018-33443-6.

32. Rivers-Moore, N.A.; Hill, T.R. A predictive management tool for blackfly outbreaks on the Orange River, South Africa. River Res. Appl. 2018, 34, 1197-1207, doi:10.1002/rra.3357. 
33. Yin, R.; Tran, V.H.; Zhou, X.; Zheng, J.; Kwoh, C.K. Predicting antigenic variants of H1N1 influenza virus based on epidemics and pandemics using a stacking model. PLoS ONE 2018, 13, doi:10.1371/journal.pone.0207777.

34. Agarwal, N.; Koti, S.R.; Saran, S.; Senthil Kumar, A. Data mining techniques for predicting dengue outbreak in geospatial domain using weather parameters for New Delhi, India. Curr. Sci. 2018, 114, 2281-2291, doi:10.18520/cs/v114/i11/2281-2291.

35. Anno, S.; Hara, T.; Kai, H.; Lee, M.A.; Chang, Y.; Oyoshi, K.; Mizukami, Y.; Tadono, T. Spatiotemporal dengue fever hotspots associated with climatic factors in taiwan including outbreak predictions based on machine-learning. Geospatial Health 2019, 14, 183-194, doi:10.4081/gh.2019.771.

36. Chenar, S.S.; Deng, Z. Development of artificial intelligence approach to forecasting oyster norovirus outbreaks along Gulf of Mexico coast. Environ. Int. 2018, 111, 212-223, doi:10.1016/j.envint.2017.11.032.

37. Chenar, S.S.; Deng, Z. Development of genetic programming-based model for predicting oyster norovirus outbreak risks. Water Res. 2018, 128, 20-37, doi:10.1016/j.watres.2017.10.032.

38. Iqbal, N.; Islam, M. Machine learning for dengue outbreak prediction: A performance evaluation of different prominent classifiers. Informatica 2019, 43, 363-371, doi:10.31449/inf.v43i1.1548.

39. Liang, R.; Lu, Y.; Qu, X.; Su, Q.; Li, C.; Xia, S.; Liu, Y.; Zhang, Q.; Cao, X.; Chen, Q., et al. Prediction for global African swine fever outbreaks based on a combination of random forest algorithms and meteorological data. Transboundary Emer. Dis. 2020, 67, 935-946, doi:10.1111/tbed.13424.

40. Mezzatesta, S.; Torino, C.; De Meo, P.; Fiumara, G.; Vilasi, A. A machine learning-based approach for predicting the outbreak of cardiovascular diseases in patients on dialysis. Comput. Methods Programs Biomed. 2019, 177, 9-15, doi:10.1016/j.cmpb.2019.05.005.

41. Raja, D.B.; Mallol, R.; Ting, C.Y.; Kamaludin, F.; Ahmad, R.; Ismail, S.; Jayaraj, V.J.; Sundram, B.M. Artificial intelligence model as predictor for dengue outbreaks. Malays. J. Public Health Med. 2019, 19, 103-108.

42. Tapak, L.; Hamidi, O.; Fathian, M.; Karami, M. Comparative evaluation of time series models for predicting influenza outbreaks: Application of influenza-like illness data from sentinel sites of healthcare centers in Iran. BMC Res. Notes 2019, 12, doi:10.1186/s13104-019-4393-y.

43. Titus Muurlink, O.; Stephenson, P.; Islam, M.Z.; Taylor-Robinson, A.W. Long-term predictors of dengue outbreaks in Bangladesh: A data mining approach. Infect. Dis. Modelling 2018, 3, 322-330, doi:10.1016/j.idm.2018.11.004.

44. Choubin, B.; Mosavi, A.; Alamdarloo, E.H.; Hosseini, F.S.; Shamshirband, S.; Dashtekian, K.; Ghamisi, P. Earth fissure hazard prediction using machine learning models. Environmental research 2019, 179, 108770.

45. Choubin, B.; Abdolshahnejad, M.; Moradi, E.; Querol, X.; Mosavi, A.; Shamshirband, S.; Ghamisi, P. Spatial hazard assessment of the PM10 using machine learning models in Barcelona, Spain. Science of The Total Environment 2020, 701, 134474.

46. Back, T. Evolutionary algorithms in theory and practice: evolution strategies, evolutionary programming, genetic algorithms; Oxford university press: 1996.

47. Deb, K. Multi-objective optimization using evolutionary algorithms; John Wiley \& Sons: 2001; Vol. 16.

48. Zitzler, E.; Deb, K.; Thiele, L. Comparison of multiobjective evolutionary algorithms: Empirical results. Evolutionary computation 2000, 8, 173-195.

49. Ghamisi, P.; Benediktsson, J.A. Feature selection based on hybridization of genetic algorithm and particle swarm optimization. IEEE Geoscience and remote sensing letters 2014, 12, 309-313. 
50. Adrienn Dineva, A.M., Sina Faizollahzadeh Ardabili, Istvan Vajda, Shahab Shamshirband, Timon Rabczuk, Kwok-Wing Chau. Review of soft computing models in design and control of rotating electrical machines. Energies 2019, 12.

51. Mosavi, A.; Salimi, M.; Faizollahzadeh Ardabili, S.; Rabczuk, T.; Shamshirband, S.; Varkonyi-Koczy, A.R. State of the art of machine learning models in energy systems, a systematic review. Energies 2019, $12,1301$.

52. Mühlenbein, H.; Schomisch, M.; Born, J. The parallel genetic algorithm as function optimizer. Parallel computing 1991, 17, 619-632.

53. Whitley, D. A genetic algorithm tutorial. Statistics and computing 1994, 4, 65-85.

54. Horn, J.; Nafpliotis, N.; Goldberg, D.E. A niched Pareto genetic algorithm for multiobjective optimization. In Proceedings of Proceedings of the first IEEE conference on evolutionary computation. IEEE world congress on computational intelligence; pp. 82-87.

55. Reeves, C.R. A genetic algorithm for flowshop sequencing. Computers $\mathcal{E}$ operations research 1995, 22, 513.

56. Jones, G.; Willett, P.; Glen, R.C.; Leach, A.R.; Taylor, R. Development and validation of a genetic algorithm for flexible docking. Journal of molecular biology 1997, 267, 727-748.

57. Ardabili, S.; Mosavi, A.; Varkonyi-Koczy, A.R. Advances in machine learning modeling reviewing hybrid and ensemble methods. 2019.

58. Houck, C.R.; Joines, J.; Kay, M.G. A genetic algorithm for function optimization: a Matlab implementation. Ncsu-ie tr 1995, 95, 1-10.

59. Whitley, D.; Starkweather, T.; Bogart, C. Genetic algorithms and neural networks: Optimizing connections and connectivity. Parallel computing 1990, 14, 347-361.

60. Kennedy, J.; Eberhart, R. Particle swarm optimization. In Proceedings of Proceedings of ICNN'95International Conference on Neural Networks; pp. 1942-1948.

61. Poli, R.; Kennedy, J.; Blackwell, T. Particle swarm optimization. Swarm intelligence 2007, 1, 33-57.

62. Clerc, M. Particle swarm optimization; John Wiley \& Sons: 2010; Vol. 93.

63. Angeline, P.J. Using selection to improve particle swarm optimization. In Proceedings of 1998 IEEE International Conference on Evolutionary Computation Proceedings. IEEE World Congress on Computational Intelligence (Cat. No. 98TH8360); pp. 84-89.

64. Sun, J.; Feng, B.; Xu, W. Particle swarm optimization with particles having quantum behavior. In Proceedings of Proceedings of the 2004 congress on evolutionary computation (IEEE Cat. No. 04TH8753); pp. 325-331.

65. Parsopoulos, K.E.; Vrahatis, M.N. Recent approaches to global optimization problems through particle swarm optimization. Natural computing 2002, 1, 235-306.

66. Bai, Q. Analysis of particle swarm optimization algorithm. Computer and information science 2010, 3, 180.

67. Parsopoulos, K.E.; Vrahatis, M.N. Particle swarm optimization method in multiobjective problems. In Proceedings of Proceedings of the 2002 ACM symposium on Applied computing; pp. 603-607.

68. Ghamisi, P.; Couceiro, M.S.; Benediktsson, J.A.; Ferreira, N.M. An efficient method for segmentation of images based on fractional calculus and natural selection. Expert Systems with Applications 2012, 39, 12407-12417.

69. Ghamisi, P.; Couceiro, M.S.; Martins, F.M.; Benediktsson, J.A. Multilevel image segmentation based on fractional-order Darwinian particle swarm optimization. IEEE Transactions on Geoscience and Remote sensing 2013, 52, 2382-2394. 
70. Mirjalili, S.; Mirjalili, S.M.; Lewis, A. Grey wolf optimizer. Advances in engineering software 2014, 69, 4661.

71. Ardabili, S.; Mosavi, A.; Varkonyi-Koczy, A. Building Energy information: demand and consumption prediction with Machine Learning models for sustainable and smart cities. Engineering for Sustainable Future, Lecture Notes in Networks and Systems, Springer Nature Switzerland.: 2019.

72. Ardabili;, S.; Mosavi;, A.; Varkonyi-Koczy;, A. Systematic Review of Deep Learning and Machine Learning Models in Biofuels Research,. Engineering for Sustainable Future, Lecture Notes in Networks and Systems, Springer Nature Switzerland 2019.

73. Gundoshmian, T.M.; Ardabili, S.; Mosavi, A.; Varkonyi-Koczy, A.R. Prediction of combine harvester performance using hybrid machine learning modeling and response surface methodology. 2019.

74. Fotovatikhah, F.; Herrera, M.; Shamshirband, S.; Chau, K.-w.; Faizollahzadeh Ardabili, S.; Piran, M.J. Survey of computational intelligence as basis to big flood management: challenges, research directions and future work. Engineering Applications of Computational Fluid Mechanics 2018, 12, 411-437.

75. Hamilton, J.D. Time series analysis; Princeton university press Princeton, NJ: 1994; Vol. 2.

76. Ardabili, S.; Mosavi, A.; Mahmoudi, A.; Gundoshmian, T.M.; Nosratabadi, S.; Varkonyi-Koczy, A.R. Modelling Temperature Variation of Mushroom Growing Hall Using Artificial Neural Networks. Engineering for Sustainable Future, Lecture Notes in Networks and Systems, Springer Nature Switzerland. 2019.

77. Khosravi, A.; Koury, R.; Machado, L.; Pabon, J. Prediction of wind speed and wind direction using artificial neural network, support vector regression and adaptive neuro-fuzzy inference system. Sustainable Energy Technologies and Assessments 2018, 25, 146-160.

78. Amid, S.; Mesri Gundoshmian, T. Prediction of output energies for broiler production using linear regression, ANN (MLP, RBF), and ANFIS models. Environmental Progress E Sustainable Energy 2017, 36, 577-585.

79. Hossain, M.A.; Ayodele, B.V.; Cheng, C.K.; Khan, M.R. Artificial neural network modeling of hydrogen-rich syngas production from methane dry reforming over novel Ni/CaFe $2 \mathrm{O} 4$ catalysts. International Journal of Hydrogen Energy 2016, 41, 11119-11130.

80. Taghavifar, H.; Mardani, A. Wavelet neural network applied for prognostication of contact pressure between soil and driving wheel. Information Processing in Agriculture 2014, 1, 51-56.

81. Sharabiani, V.; Kassar, F.; Gilandeh, Y.; Ardabili, S. APPLICATION OF SOFT COMPUTING METHODS AND SPECTRAL REFLECTANCE DATA FOR WHEAT GROWTH MONITORING. The Iraqi Journal of Agricultural Science 2019, 50, 1064-1076.

82. Mirzazadeh, A.; Abdollahpour, S.; Mahmoudi, A.; Bukat, A. Intelligent modeling of material separation in combine harvester's thresher by ANN. International Journal of Agriculture and Crop Sciences 2012, 4, 1767-1777.

83. Khalesi, S.; Mahmoudi, A.; Hosainpour, A.; Alipour, A. Detection of walnut varieties using impact acoustics and artificial neural networks (ANNs). Modern Applied Science 2012, 6, 43.

84. Reshadsedghi, A.; Mahmoudi, A. Detection of almond varieties using impact acoustics and artificial neural networks. International Journal of Agriculture and Crop Sciences 2013, 6, 1008.

85. Hassoun, M.H. Fundamentals of artificial neural networks; MIT press: 1995.

86. Jang, J.-S. ANFIS: adaptive-network-based fuzzy inference system. IEEE transactions on systems, man, and cybernetics 1993, 23, 665-685. 
87. Faizollahzadeh_Ardabili; Mahmoudi, A.; Mesri Gundoshmian, T. Modeling and simulation controlling system of HVAC using fuzzy and predictive (radial basis function, RBF) controllers. Journal of Building Engineering 2016, 6, 301-308.

88. Amid, S.; Mesri Gundoshmian, T. Prediction of output energy based on different energy inputs on broiler production using application of adaptive neural-fuzzy inference system. Agri. Sci. Dev 2016, 5, 14-21.

89. Ardabili, S.; Mosavi, A.; Dehghani, M.; Várkonyi-Kóczy, A.R. Deep learning and machine learning in hydrological processes climate change and earth systems a systematic review. In Proceedings of International Conference on Global Research and Education; pp. 52-62.

90. Nosratabadi, S.; Mosavi, A.; Keivani, R.; Ardabili, S.; Aram, F. State of the art survey of deep learning and machine learning models for smart cities and urban sustainability. In Proceedings of International Conference on Global Research and Education; pp. 228-238.

91. Güler, I.; Übeyli, E.D. Adaptive neuro-fuzzy inference system for classification of EEG signals using wavelet coefficients. Journal of neuroscience methods 2005, 148, 113-121.

92. Chang, J.-R.; Wei, L.-Y.; Cheng, C.-H. A hybrid ANFIS model based on AR and volatility for TAIEX forecasting. Applied Soft Computing 2011, 11, 1388-1395.

93. Chang, F.-J.; Chang, Y.-T. Adaptive neuro-fuzzy inference system for prediction of water level in reservoir. Advances in water resources 2006, 29, 1-10.

94. Moghaddamnia, A.; Gousheh, M.G.; Piri, J.; Amin, S.; Han, D. Evaporation estimation using artificial neural networks and adaptive neuro-fuzzy inference system techniques. Advances in Water Resources 2009, 32, 88-97.

95. Çaydaş, U.; Hasçalık, A.; Ekici, S. An adaptive neuro-fuzzy inference system (ANFIS) model for wireEDM. Expert Systems with Applications 2009, 36, 6135-6139.

96. Yadav, D.; Chhabra, D.; Gupta, R.K.; Phogat, A.; Ahlawat, A. Modeling and analysis of significant process parameters of FDM 3D printer using ANFIS. Materials Today: Proceedings 2020, 21, 1592-1604.

97. Faizollahzadeh_Ardabili; Mahmoudi, A.; Gundoshmian, T.M.; Roshanianfard, A. Modeling and comparison of fuzzy and on/off controller in a mushroom growing hall. Measurement 2016, 90, 127-134.

(C) 2020 by the authors. Submitted for possible open access publication under the terms and conditions of the Creative Commons Attribution (CC BY) license (http://creativecommons.org/licenses/by/4.0/). 